\title{
\& ห
}

تمكين الأخصائين الرياضيين وعلاقته بالرضا الوظيفى بادار ات رعاية شباب كليات جامعة أسيوط

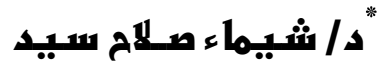

تقدمت الحياة مع نهاية القرن العشرين تقدماً هائلاً في جميع العلوم و المجالات عامــة هاءة

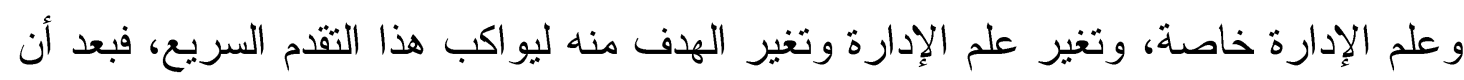
كان الهدف من الإدارة هو وضع الأهداف للعاملين لتنفيذها، و القو اعد و اللوائح لكي يسـيروا عليها، و الرقابة لضمان التتفيذ، أصبح الهدف هو استثارة حماس العاملين و إفســاح المجـــال

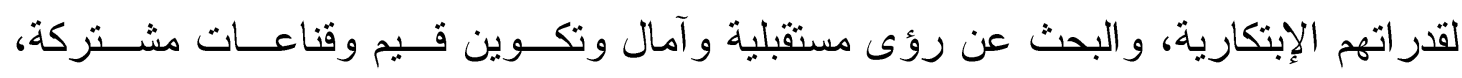

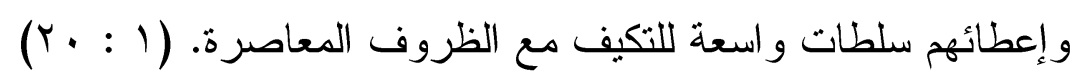
ونتيجة للتحو لات السريعة والعميقة غير المسبوقة بدأت في الظهور قوي ومتغيــرات

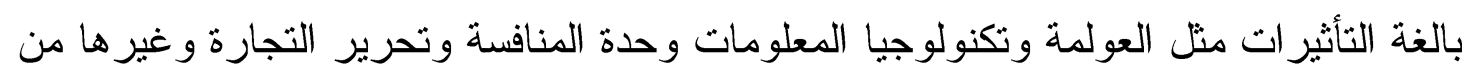

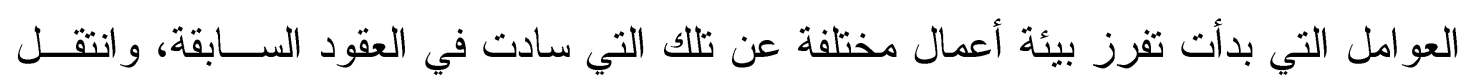
العالم من عصر الصناعة إلى عصر المعلومات وهو ما عرف بالموجة الثالثة للإدارة و التيـي

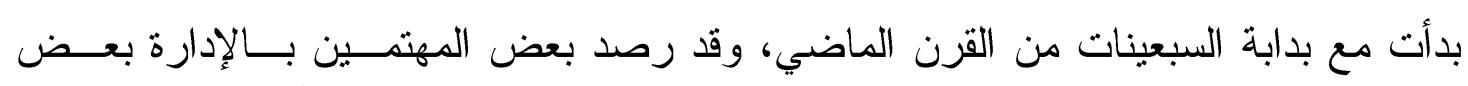
خصائص هذه الحقبة الجديدة التي تلعب فيها القيم غير الملموسة دور حيوياً في نجاح الهيئات

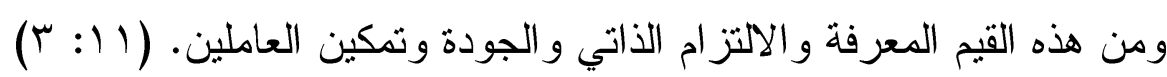

وقد كان على الإنسان مسايرة هذا التقدم والتغير والاستعداد له بتوفير وتجهيز المناخ وهن وهنين

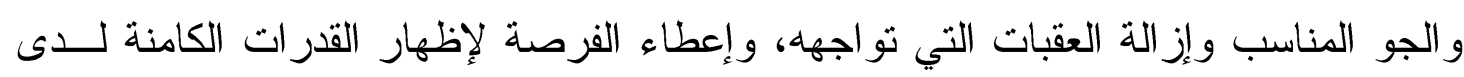
الرؤساء و المرؤوسين، وتعديل سلوك الأفر اد و أفكار هم.

ويعتبر تمكين العاملين هو الصيحة التي تتردد مؤخراً في مجال تطور الفكر الإداري

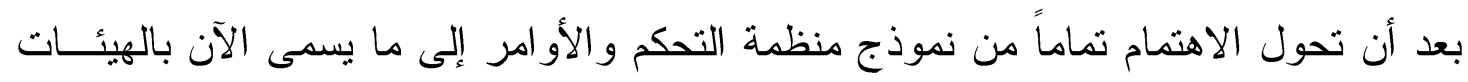
الممكنة، ومن هذا السياق يجئ مدخل تمكين العالمين ذو صلة كبيرة باتجاهات التطوير السائدة

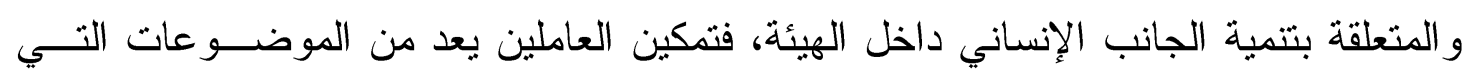
برزت على الساحة و لاقت رواجاً كبيراً من الناحية النظرية و التطبيقية، ويتميز هذا المــدخل فعلئ

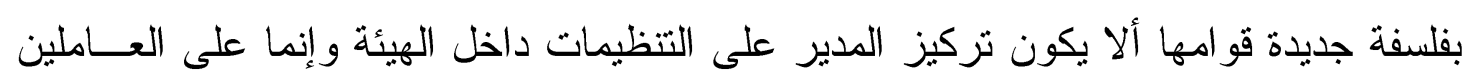

في المقام الأول. (v: (

* أستاذ مساعد بقسم الإدارة الرياضية و التزويح- كلية التربية الرياضية- جامعة أسيوط مجلة أسيوط لعلوم وفنون التربية الرياضية 
ويشكل الاهتمام بمفهوم تمكين العاملين عنصر اً أساسياً وحاسماً للهيئات خصوصاً في

ظل الاتجاه نحو تبنى وتطبيق المفاهيم الإدارية الحديثة كادارة الجودة الشاملة، و إعادة هندسة

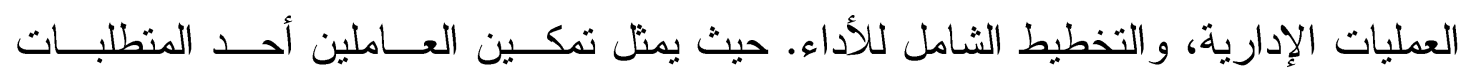
الأساسية لنجاح تطبيق المفاهيم الإدارية الحديثة. لذا فان الهيئات في حاجة ماسة لتبنى ثقافــة تتظيمية وممارسات إدارية حديثة تتلاعم مع المتطلبات و التطور ات المعاصرة، وتعتبر دراسة

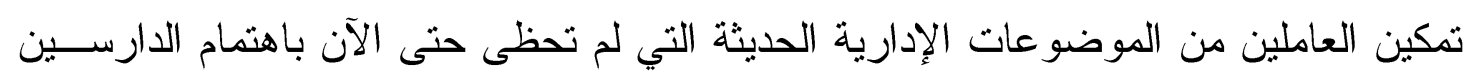

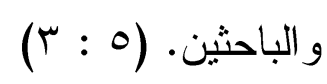

و التمكين حالة عقلية ونفسية بطيئة التكوين يأخذ عدة أشكال ويتحقق بعدة وسائل أهمها

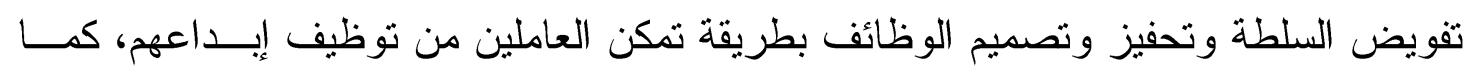
يقوم على تكوين فرق عمل فعالة بطلق عليها مجموعات العمل المستقلة، ويرتكز مضــــونه على فكرة الالتزام الداخلي ويعني الالتزام توليد الطاقة البشرية وأعمال العقل البشري، كمـــا

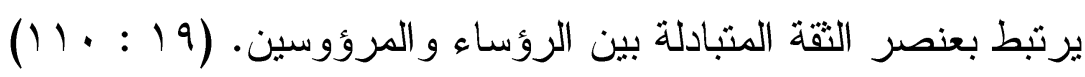
وترى "خولة خميس عبيد" أن التمكين هو مكون تحفيزي ذو أربع أبعــاد (الأهميــة،

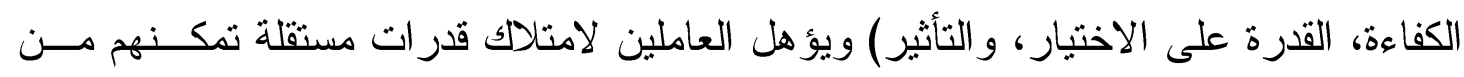
اتخاذ القرار بما يتتاسب مع أهداف المنظمة. (Y: ويوضح "جمال محمد على" أن التمكين في المجال الرياضي يقصد به جعل العـاملين في المجال الرياضي قادرين على وضع الأهداف الخاصة بعملهم والقدرة على اتخاذ القــرار

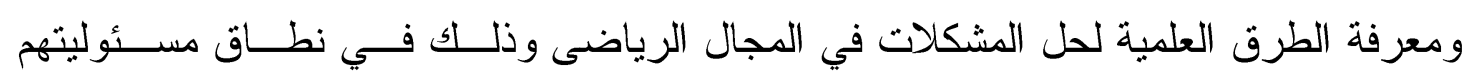
وسلطاتهم. (1:1.10)

و لأهمية تمكين العاملين تناولته العديد من الدراسات منها دراسة "محمد عبد العظـيم

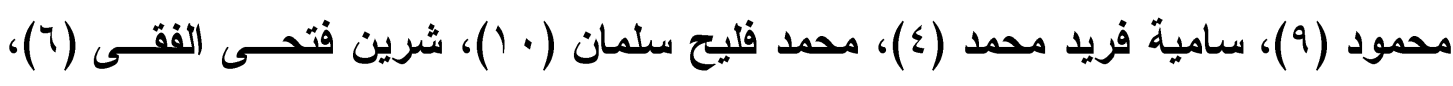

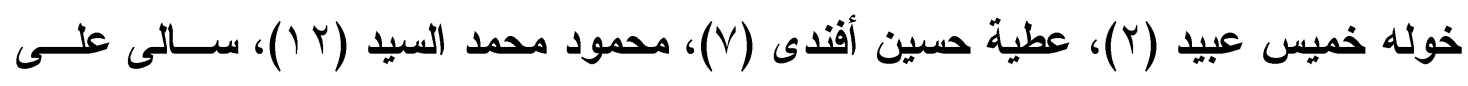

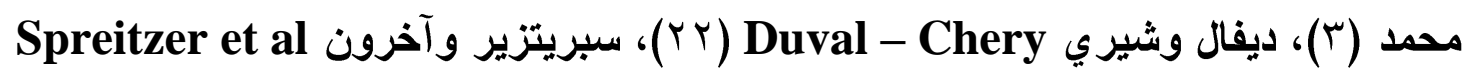

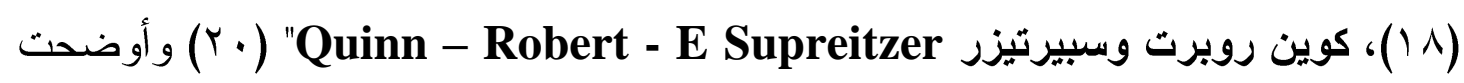
هذه الدراسات أن التمكين يؤثر على دافعية انجاز العاملين وزيــادة مســتوى الأداء وانجــاز

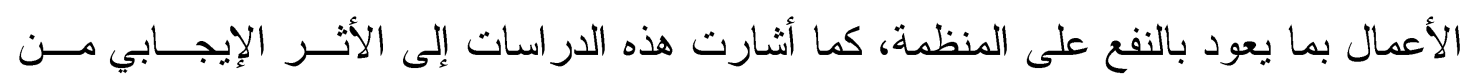
تمكين العاملين فى ولاءهم تجاه المنظمة وبناء فريق عمل فعال، كما يشعر العاملين للإحساس بالأمن الأمان والاستقر ار مما يشجع العاملين للمشاركة فى رؤية الإدارة العليا. 


\section{$\varepsilon r \wedge$}

لذا يعتبر تمكين العاملين هام وضرورى لإدار ات رعاية شباب كليات جامعة أســيوط وذلك لأنها هيئات رياضية مسئولة عن الأنشطة المختلفة التي تتظمها كليات الجامعة ومسئولة أيضاً عن النمو الثامل و المتكامل و المتزن للفرد في ضوء الأسلوب العلمى الصحيح في إدارة الأنشطة.

وبذلك تكون إدارة رعاية شباب الكليات في حاجة ماسة إلى أجهزة إدارية ذات فاعلية أكبر و أكثر كفاءة وقدرة على قيادة العمل الثبابي و الرياضي، فأدت هذه الأسباب إلى ضرورة

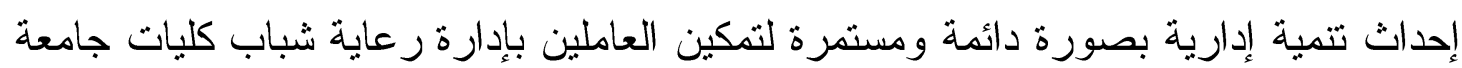
أسيوط لمو اكبة الفكر الإداري المتحضر وتمكينه من النهوض بوظائفه و الإسهام فـــي التنميــة

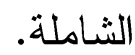

ويتطلب التتفيذ الفعال للتمكين رضا وظيفي من العاملين بالهيئة التي يعمل بها. حيث يتطلب تطبيق التمكين تغيير ثقافة التنظيم القديمة وتبنى ثقافة تنظيمية جديدة مساندة للتمكـين.

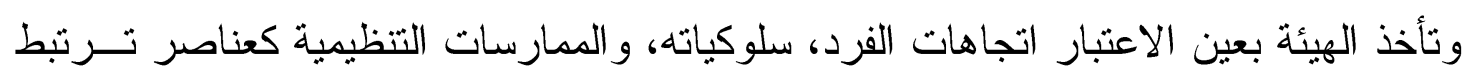
بحياة الهيئة و الفرد.

كذلك هناك العديد من العوامل التي تشاهم في التأثير على الرضا الوظيفي للأفراد في وظائفهم منها ما هو متعلق بالفرد نفسه مثل (السن، النوع، مدة الخدمة، درجة التعليم، أهميــة

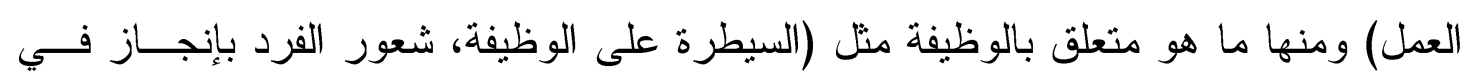

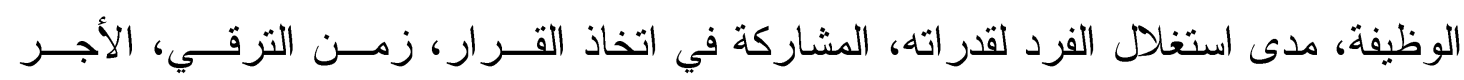

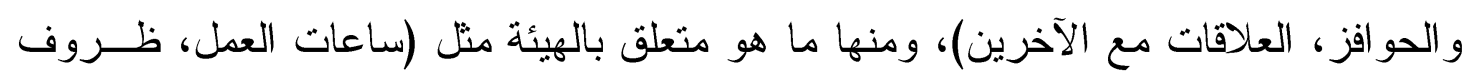

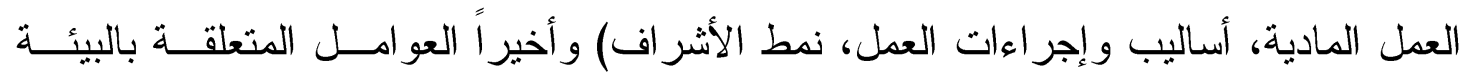

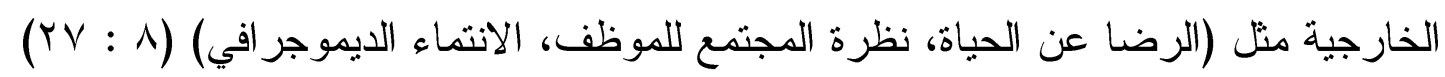
ورضا العملاء الخارجيين (الممارسين) لا يمكن تحقيقه دون أن يتحقق رضاء العملاء الداخليين (العاملين) و الذي يعتبر مفتاح الهيئة نحو تحقيق خدمة متميزة، ومن العو امل الهامــة

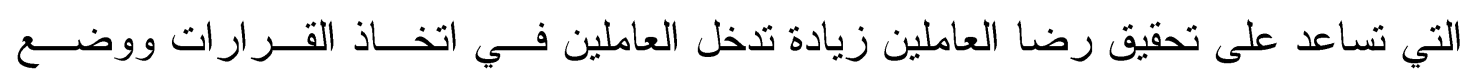
الأهداف و السياسات وكذلك ثقييم الأداء. (10 : I V (10). وترجع أهمية الرضا الوظيفي أنه يعتبر من المفاهيم بالغة الأثر في الفــرد والهيئـة

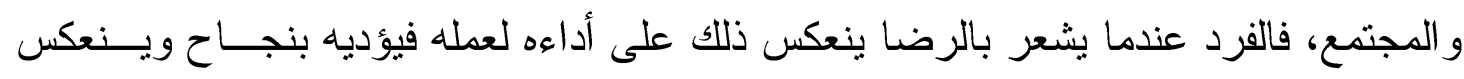

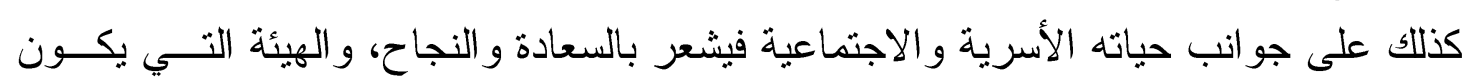
موظفو ها راضيين عن وظائفهم تتمتع بالاستقر ار والقدرة على تحقيق مستويات إنتاجية عالية 


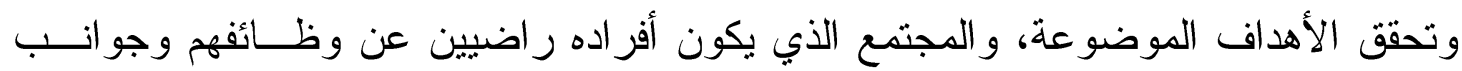

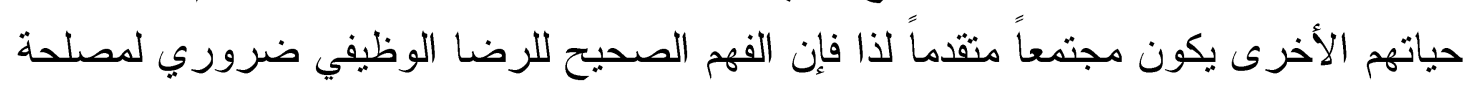

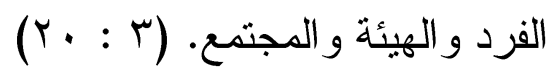

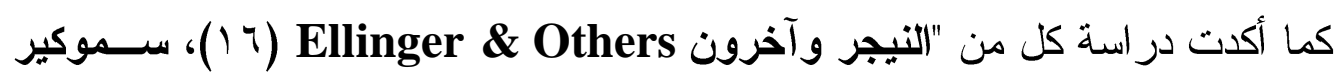

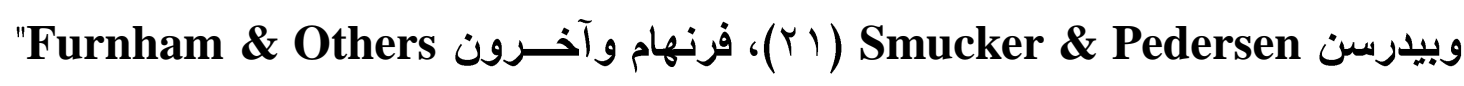

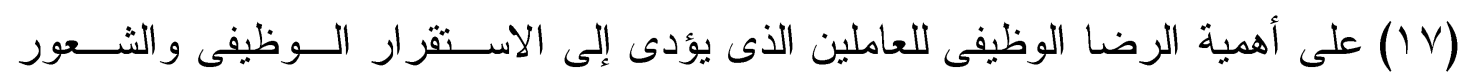

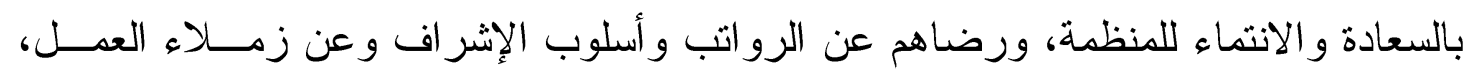

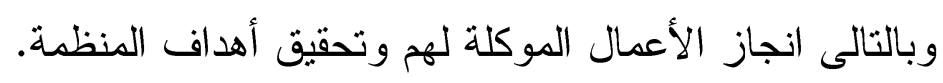

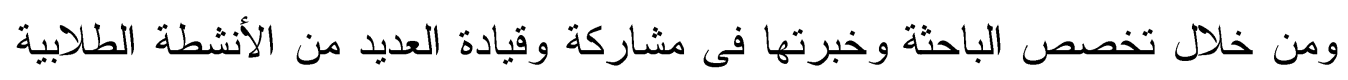

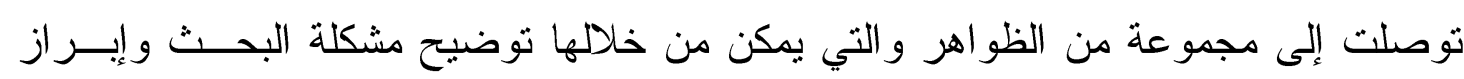

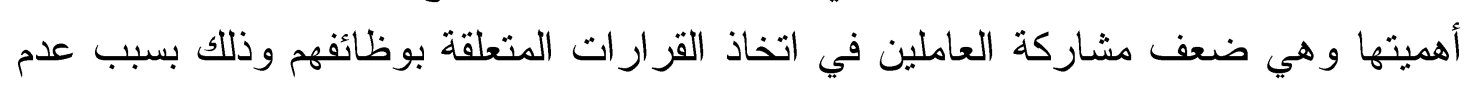

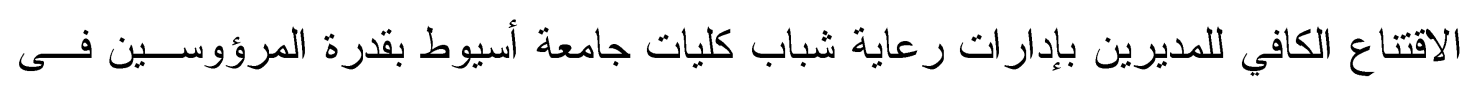

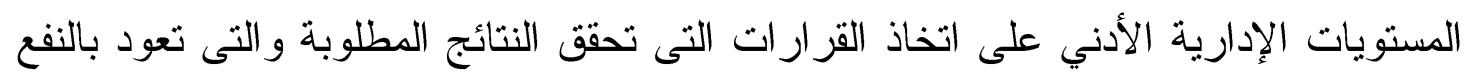

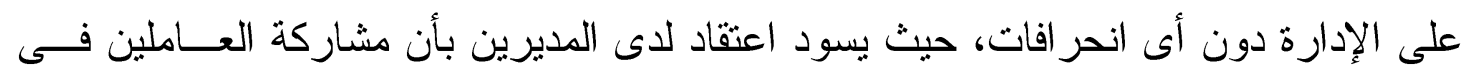

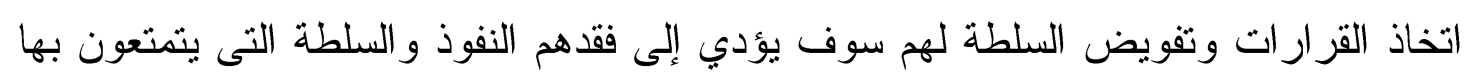

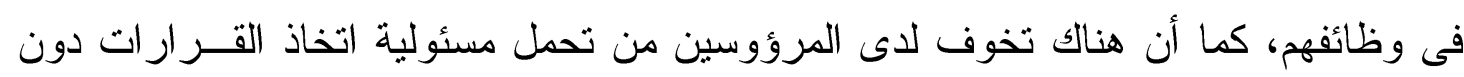

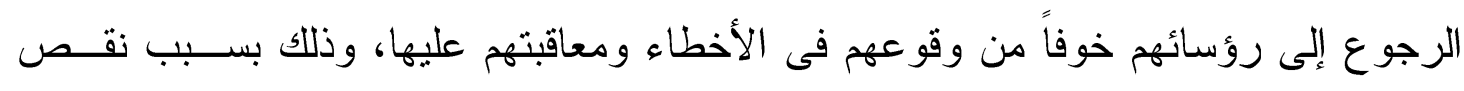

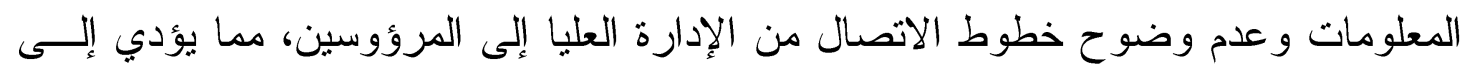

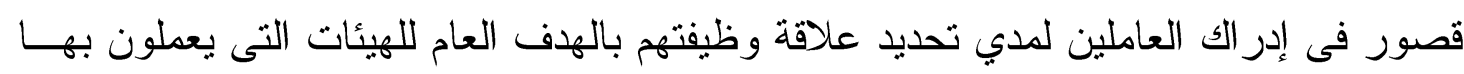
وتأثير ذلك على مستوى الرضا الوظيفي لديهر.

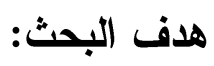

يهدف البحث إلى التعرف على علاقة تمكين الأخصائيين الرياضيين بالرضا الوظيفى

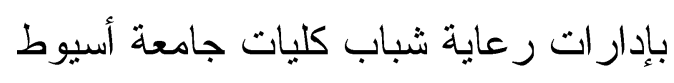
تساؤلات البحث: ا- ما درجة نو افر أبعاد تمكين الأخصائيين الرياضيين فى إدار ات رعاية شباب كليات جامعة أسيوط؟ ما درج ץ- ما درجة تو افر الرضا الوظيفي للأخصائيين الرياضيين فى إدارات رعاية شباب كليـات جامعة أسيوط؟ مجالة أسيوط لعلوم وفنون التربية الرياضية 


\section{$\varepsilon r$.}

ب- ما العلاقة بين أبعاد تمكين الأخصائيين الرياضيين و الرضا الوظيفي بإدار ات رعاية شباب

$$
\begin{aligned}
& \text { كليات جامعة أسيوط؟ } \\
& \text { مصطلحات البحث: }
\end{aligned}
$$

- Empowerment التمكين -

هو إعطاء العاملين الصلاحيات و المسئوليات ومنحهم الحرية لأداء العمل بطــــــتهن

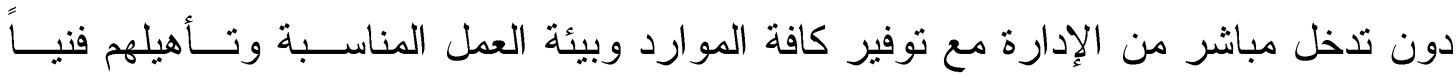

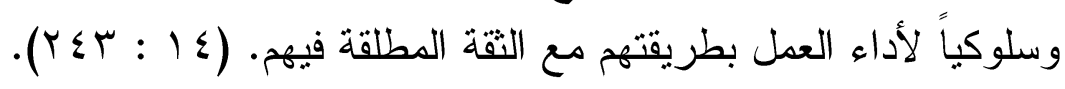

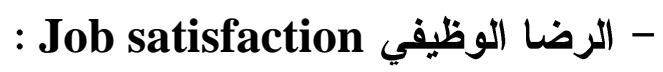
هو الشعور النفسي بالقناعة والارتباح لإشباع الحاجات و الرغبات و التوقعات مع العمل

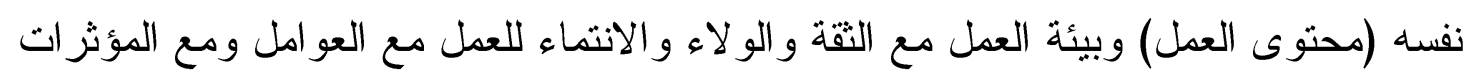

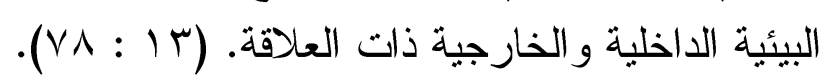
- المثاركين: شارك فى البحث الأخصائيين الرياضيين فى إدار ات رعاية شــباب كليــات جامعــة

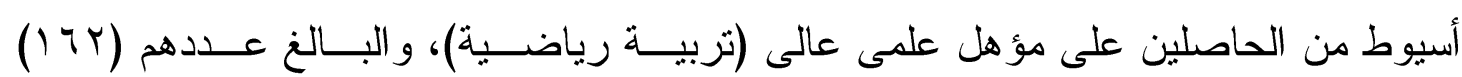

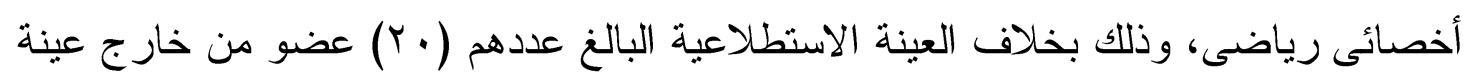

جدول (1) (1) (1) (1)

البحث. جدول (1)

\begin{tabular}{|c|c|c|c|c|}
\hline الن_111ة المثٔوبة & العبنة & 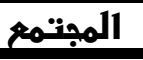 & الكلية & م \\
\hline$\% 7$. & 9 & 10 & علوم & 1 \\
\hline$\%$ or & $\wedge$ & 10 & هندسة & $r$ \\
\hline$\% \leq 0$ & 9 & $r$. & طب بشرى & $\mu$ \\
\hline$\% \circ \wedge$ & $1 \varepsilon$ & rz & طب بيطرى & $\varepsilon$ \\
\hline$\% 7 \leq$ & V & 11 & صيدلة & 0 \\
\hline$\% 7$. & 11 & r. & تزبية & 7 \\
\hline$\% \leq \wedge$ & $1 \cdot$ & YI & تجارة & V \\
\hline$\% \wedge \wedge$ & $1 \varepsilon$ & 17 & حقوق & $\Lambda$ \\
\hline$\% \vee 0$ & Ir & 17 & تزبية رياضية & 9 \\
\hline$\% \circ \wedge$ & V & Ir & خدمة اجتماعية & 1. \\
\hline$\% \vee r$ & 11 & 10 & آداب & 11 \\
\hline$\% 9$. & 11 & $r$. & زر اعة & IY \\
\hline$\% \wedge 9$ & $\wedge$ & 9 & تمريض & M \\
\hline$\% \wedge 9$ & $\Lambda$ & 9 & تزبية نو عية & $1 \varepsilon$ \\
\hline$\% 9$. & 9 & 1. & حاسبات ومعلومات & 10 \\
\hline$\%$ TV & $17 r$ & $r \leq r$ & المجمو ع & \\
\hline
\end{tabular}

بيان عددى لعينة البحث 


\section{$\{r 1$}

أسلوب جمع البيانات:

استخدمت الباحثة الاستبيان كوسيلة لجمع البيانات اللازمة لتحقيق هدف البحث عـن

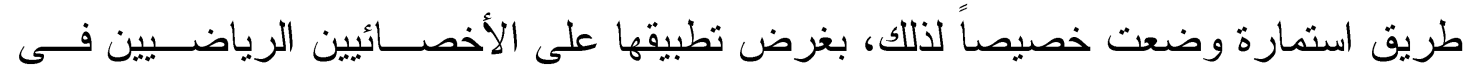

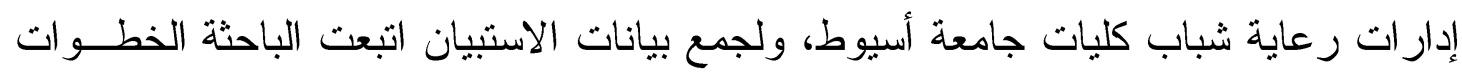

التالية:

$$
\text { جمع البيانات مكتبياً: }
$$

وذللك بالإطلاع على المراجع العلمية التي اشتملت بعض الكتب و البحـــوث العلميــة العربية والأجنبية بهدف بناء الإطار الفكرى و النظرى لموضوع تمكين الأخصائين الرياضبين وجميع العو امل و المتغير ات المؤثرة و المتأثرة بهـ. جمع البيانات ميدانياً:

وذلك من خلال جمع البيانات الميدانية وتحليلها و استخلاص النتائج التي توضح تمكين العاملين و أثر ها على الرضا الوظيفى لدى الأخصائين الرياضيين بإدار ات رعاية شباب كليات

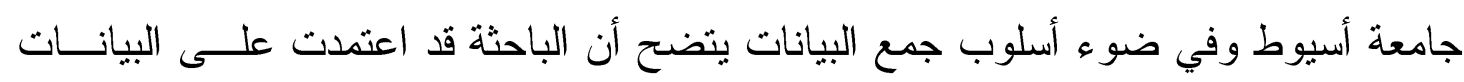
الأولية و التي تمثلت في نتائج ما حصلت عليها من إجابات الأخصائيين الرياضيين فى إدار ات رعاية شباب كليات جامعة أسيوط، على استمار ات الاستقصاء هذا بالإضـافة إلـى البيانــات

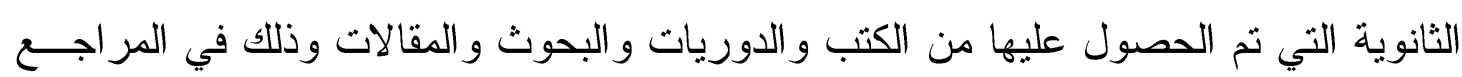
العربية والأجنبية التي أتبحت مما يسر للباحثة بناء الجوانب المنهجية للبحث، وبناء عليه قامت الباحثة بتصميم استمارة استبيان تضم المحاور المقترحة مرفق (Y)، ثم عرضها على مجموعة

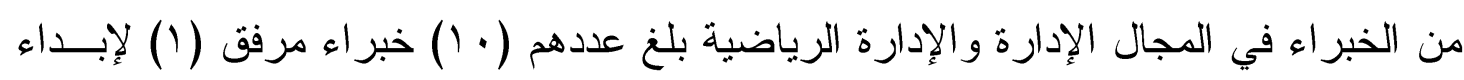
الر أي من حيث: الخيز أغي - مدى مو افقة الخبر اء لمحاور استبيان.

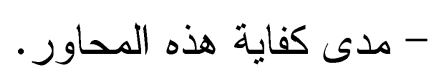
- تعديل أو حذف أو إضافة محاور أخرى. وتوصلت الباحثة إلى المحاور الأساسية لاستمارة الاستبيان التي تحقق أهداف الدراسة الحالية، ثم قامت الباحثة بصياغة عبار ات كل محور فتضمنت المحـــاور العبــار ات التاليــة:

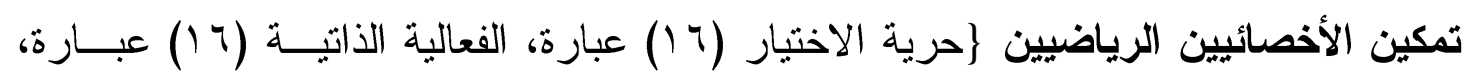

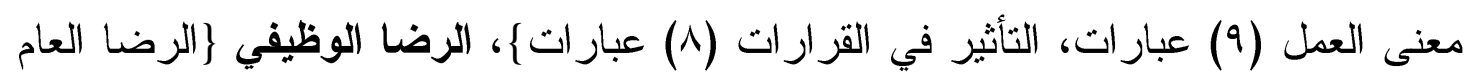

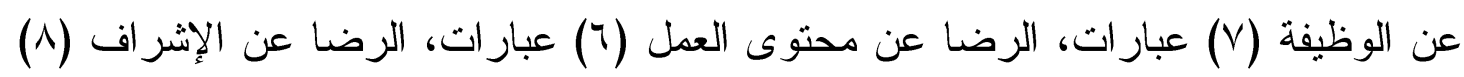




\section{\& r}

عبار ات، الرضا عن نمط الترقية (؟) عبار ات، الرضا العام عن الر اتب (آ) عبار ات، الرضا

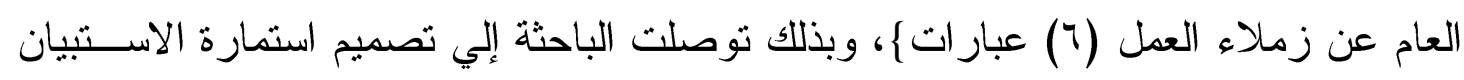

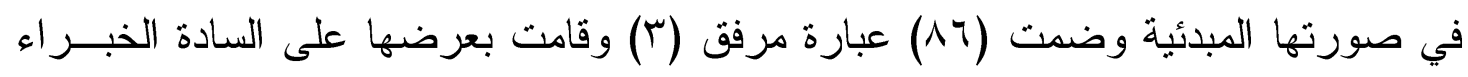

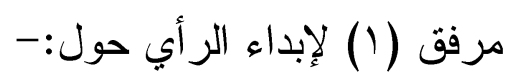

- مدى مناسبة الموضو عات المقترحة باءئ بالنسبة للمحور . - ارتباط كل موضوع بالمحور الموضو الرئيسي له.

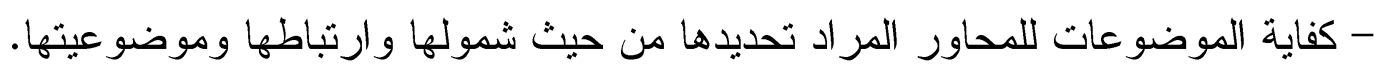

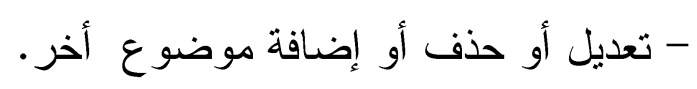

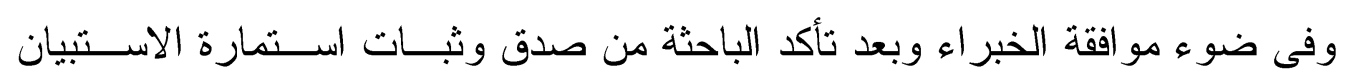

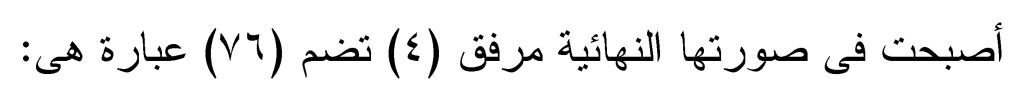

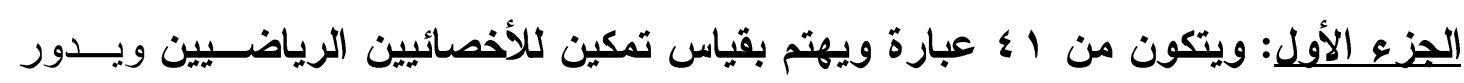
حول در اسة المتغير ات التالية:

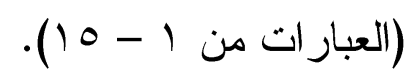
أسؤ الأ 10
حرية الاختيار .

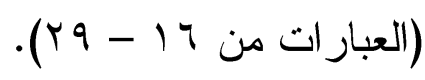

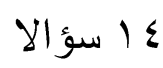
الفعالية الذاتية.
T أسئلة
معنى العمل
T أسئلة
التأثير في القرار ات
0

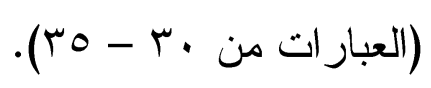

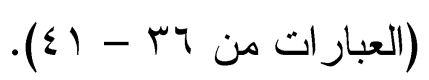
توني

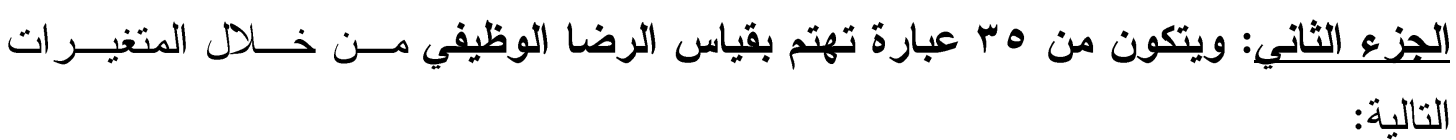

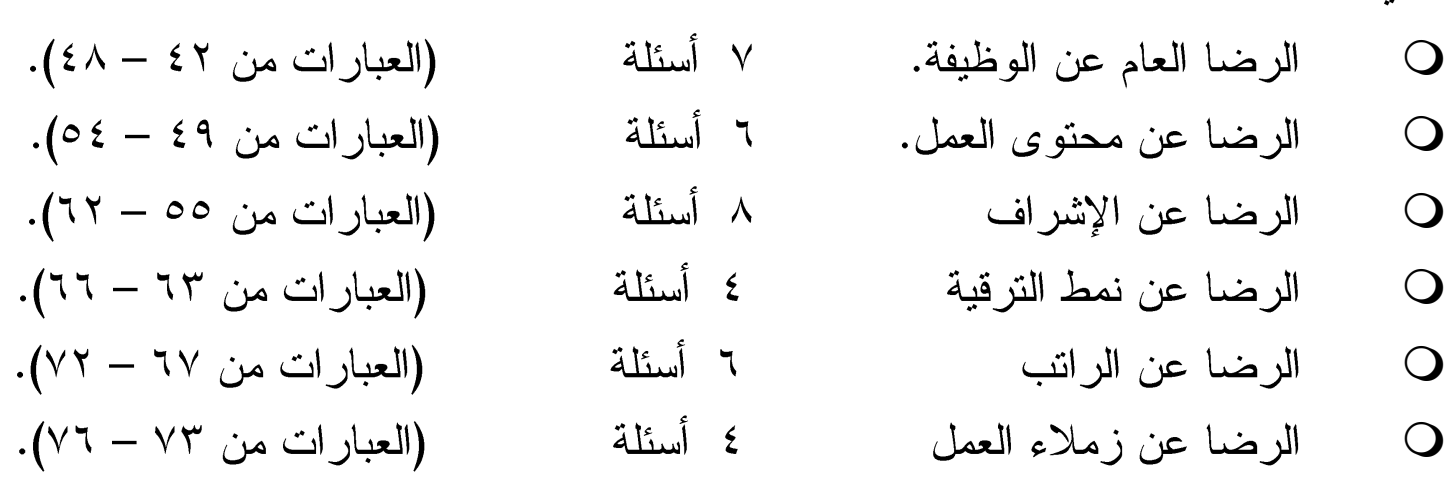

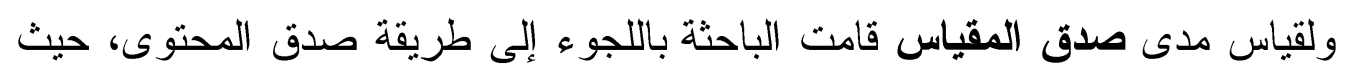

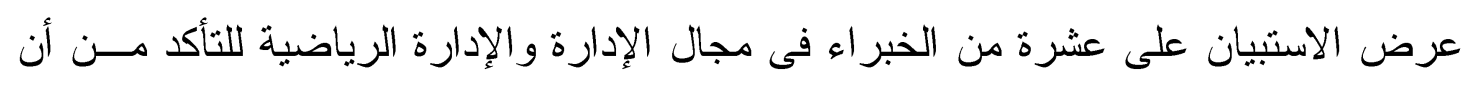

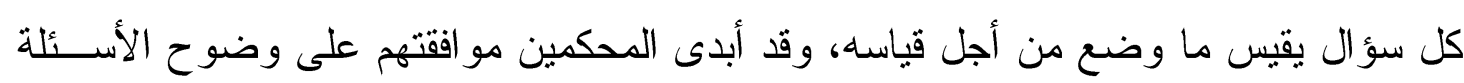

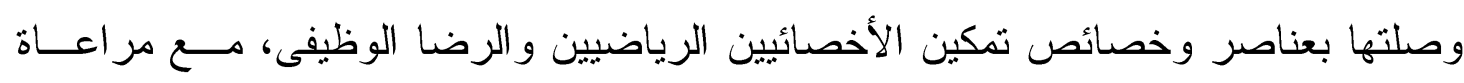




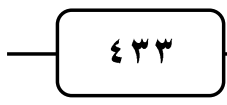

بعض الملاحظات المرتبطة بصياغة عدد من العبارات، وقامت الباحثة بحساب معامل الاتساق بين مجموع المحور و المجموع الكلى لاستمارة الاستبيان، ويتضمن جدول (Y) نتــائج هــذا

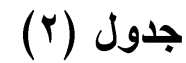

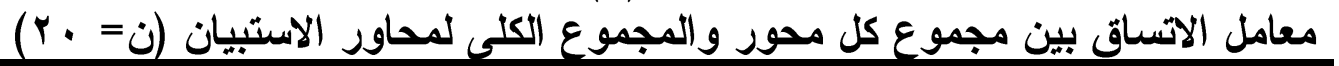

\begin{tabular}{|c|c|c|}
\hline معامل الاتساقة & المهاور الفر عية & المهاور الرئيسية \\
\hline$\cdot, \wedge \mu$ & حرية الاختيار & \multirow{4}{*}{ التمكين للأخصائيين } \\
\hline$\cdot, 97$ & الفعالية الذاتية & \\
\hline$\cdot, 9 \mathrm{~V}$ & معنى العمل & \\
\hline$\cdot, \wedge$. & التأثئير في القرارات & \\
\hline$\cdot, 91$ & الرضا العام عن الوظيفة & \multirow{6}{*}{ الرضا الوظيفي } \\
\hline$\cdot, \wedge \Lambda$ & الرضا العام عن محتوى العمل & \\
\hline$\cdot, 9 \mathrm{~V}$ & الرضا العام عن الإثر اف & \\
\hline$\cdot, \wedge 9$ & الرضا العام عن نمط الترقية & \\
\hline$\cdot, \Lambda \mathrm{V}$ & الرضا العام عن الر اتب & \\
\hline$\cdot, \wedge 9$ & الرضا العام عن زملاء العمل & \\
\hline
\end{tabular}

وقد ثبتت معنويته إحصائيا مما يشير إلى صدق المقياس وفقا لآراء المتخصصين علميا.

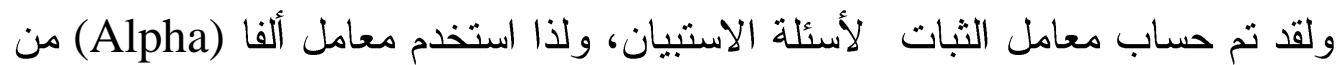
خلال حزمة SPSS، وذلك لبحث مدى الاعتماد على نتائج الدر اسة الميدانية فى تعميم النتائج،

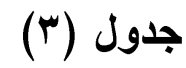

ويتضح ذلك من خلال جدول (r)

معامل الثبات ألفاء) لمحاور لإستمارة الاستبيان (Alpha) لمهان

\begin{tabular}{|c|c|c|}
\hline معامل الثبات & المحاور الفر عية & المهاور الرئيسية \\
\hline.,$Y 0 \Omega$ & حرية الاختيار & \multirow{4}{*}{ التمكين للأخصائيين } \\
\hline$\cdot, \vee \vee \wedge 0$ & الفعالية الذاتية & \\
\hline$\cdot, 771$ & معنى العمل & \\
\hline$\cdot, \mathrm{VOA}$ & التأثير في القرارات & \\
\hline$\cdot, \wedge \Sigma 1$ & الرضا العام عن الوظيفة & \multirow{6}{*}{ الرضا الوظيفي } \\
\hline$\cdot, 9 \cdot 1$ & الرضا العام عن محتوى العمل & \\
\hline$\cdot, \vee \vee \wedge O$ & الرضا العام عن الإشر اف & \\
\hline$\cdot, \wedge \leqslant 1$ & الرضا العام عن نمط التزقية & \\
\hline •, & الرضا العام عن الر اتب & \\
\hline$\cdot, \vee \vee 99$ & الرضا العام عن زملاء العمل & \\
\hline
\end{tabular}

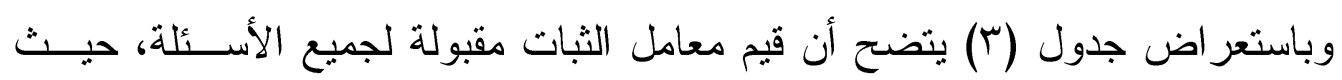

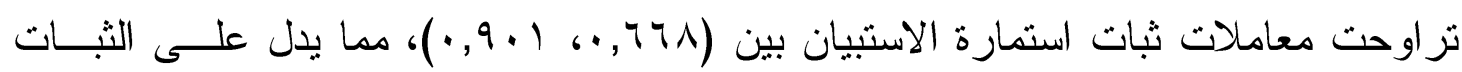


لجميع محاور الاستبيان، وبالتالى يمكن القول أنها معاملات ذات دلالة جيدة لأغر اض البحث ويمكن الاعتماد عليها فى تعميم النتائج. تطبيق استمارة الاستبيان:

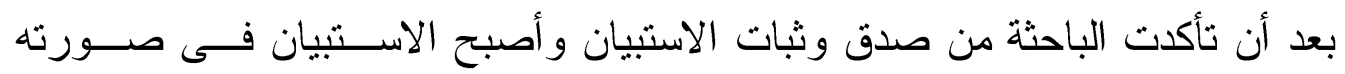

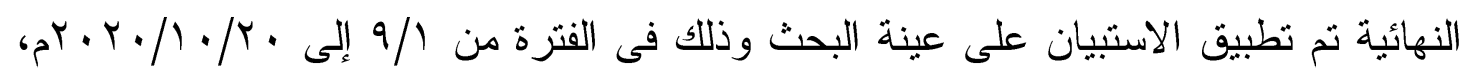

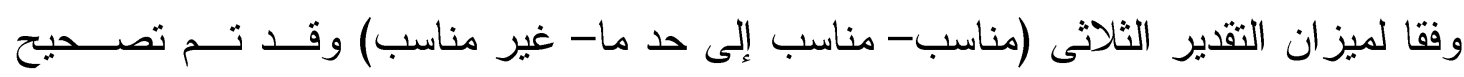

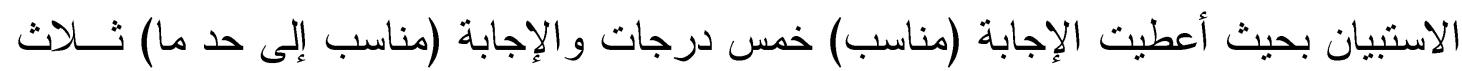
درجات و الإجابة (غير مناسب) درجة و احدة وتم تجميع البيانات وتتظيمها وجدولتها ومعالجنها ولإنها إحصائيا.

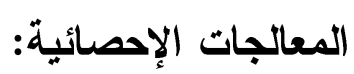

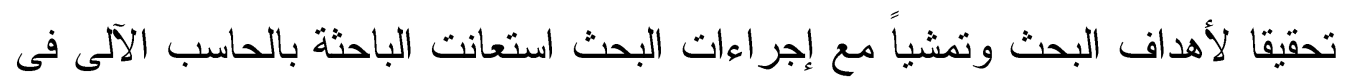

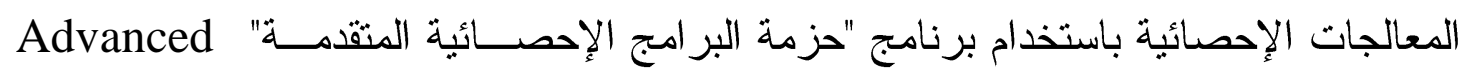
statisticeal Analysis Paclcase (A.S.A.P.)

$$
\text { - - معامل ثبات ألفائة. كرنباخ. }
$$

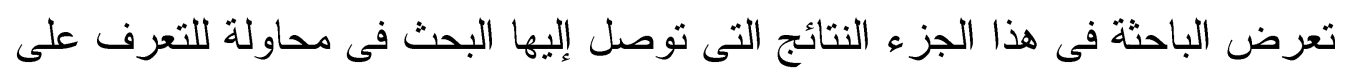

\begin{tabular}{|c|c|c|c|c|c|}
\hline اتناذ القراراتثرات & العمل. & الذاتنية:لة & الافتيار. هرية & 1لكاليات & م \\
\hline 19 & $\Lambda$. & V) & $V$. & علوم (ن=9) & 1 \\
\hline 79 & $\mathrm{Vq}$ & 19 & 71 & هندسة (ن= $)$ & $r$ \\
\hline AV & 1) & VV & $V \cdot$ & طب بشرى (ن=9) & r \\
\hline$V 7$ & VI & 70 & VI & طب بيطرى (ن=؛ 1) & $\varepsilon$ \\
\hline 70 & $V^{\mu}$ & 01 & 09 & صيدلة (ن= & 0 \\
\hline VY & $\mathrm{Vr}$ & $T \varepsilon$ & 71 & تربية (ن=A & 7 \\
\hline Ar & $\Delta r$ & 79 & $V \varepsilon$ & تجارة (ن=• & V \\
\hline Tr & $V$. & 71 & זי & حقوق (ن=ـ 1) & $\wedge$ \\
\hline
\end{tabular}

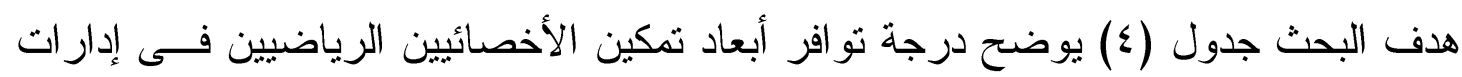
رعاية الشباب بكليات جامعة أسيوط:

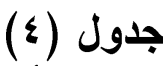

النسبة المئوية للارجة المقدرة لمحاور تمكين الأخصائيين الرياضيين لإدارات رعاية شباب كليات جامعة أسيوط المين

مجالة أسيوط لعلوم وفنون التربية الرياضية 


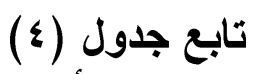

النسبة المئوية للارجة المقدرة لمحاور تمكين الأخصائيين الرياضيين لإدارات رعاية شباب كليات جامعة أسيوط

\begin{tabular}{|c|c|c|c|c|c|}
\hline 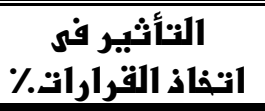 & العمل. & الذاتية:لية & هرية & الكليات & م \\
\hline $\mathrm{Vq}$ & $\Lambda \mathrm{VV}$ & 79 & 70 & تربية رياضية (ن=r I ) & 9 \\
\hline$\wedge$. & Ar & $V V$ & VY & خدمة اجتماعية (ن= V=) & 1. \\
\hline $7 \varepsilon$ & $V 7$ & $4 \pi$ & 70 & آداب (ن=11) & 11 \\
\hline 79 & 77 & TV & $\pi$ & زر اعة (ن=ي ا) & Ir \\
\hline$V \mu$ & VI & $\mathrm{V} \cdot$ & $7 V$ & تمريض (ن=N) & M \\
\hline 9. & $\wedge \wedge$ & 10 & $\mathrm{VI}$ & تربية نوعية (ن=人) & $1 \varepsilon$ \\
\hline (1) & V) & 71 & 71 & حاسبات ومعلومات (ن=9) & 10 \\
\hline
\end{tabular}

يتضح من جدول (ع) ما يلى:

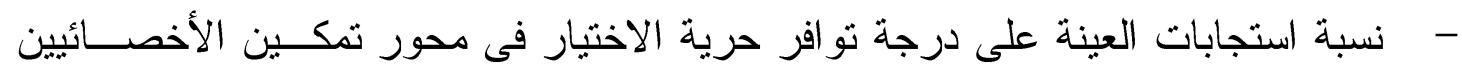

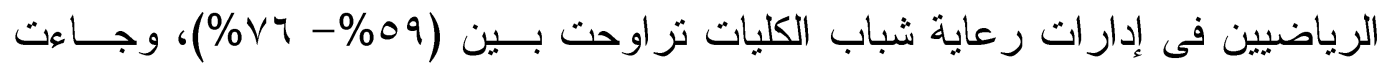

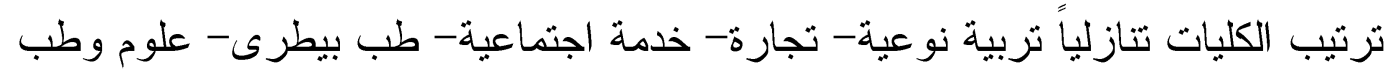

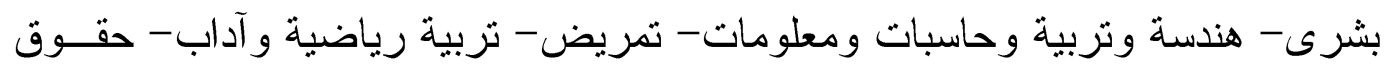
وزر اعة- صيدلة. - - نسبة استجابات العينة على درجة توافر الفعالية الذاتيــة لمحسـور تمكـين الأخصــائيين

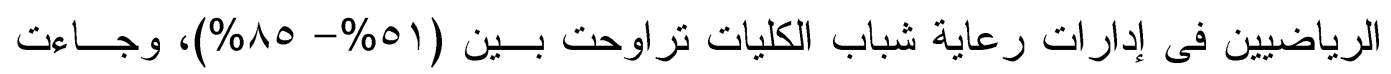

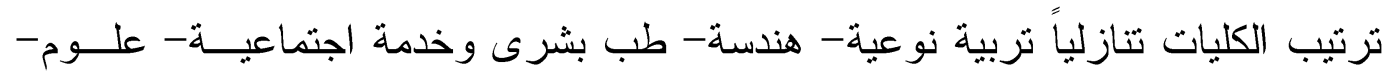

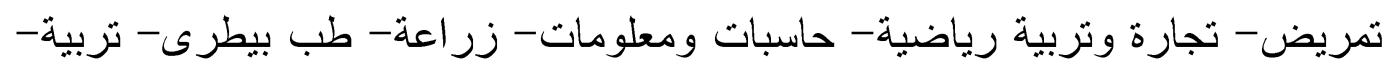

$$
\text { آداب- حقوق - صبدلة }
$$

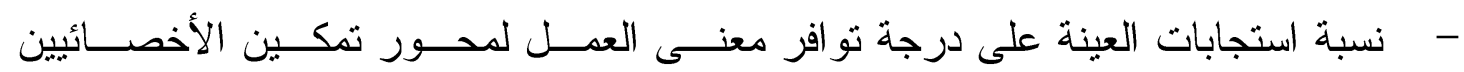

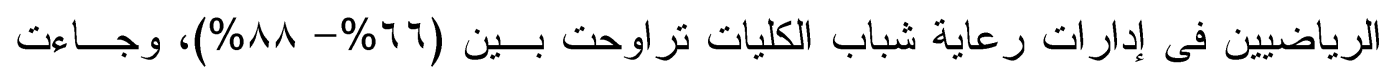

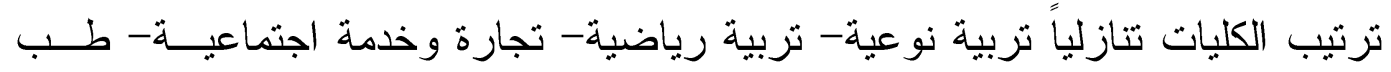

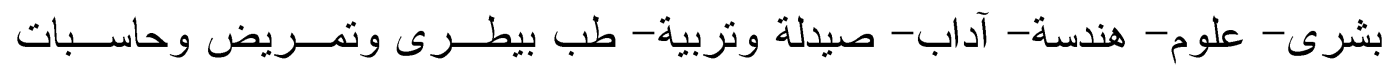

$$
\text { ومعلومات- حقوق - زر اعة. }
$$

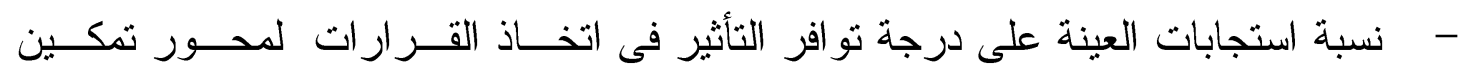

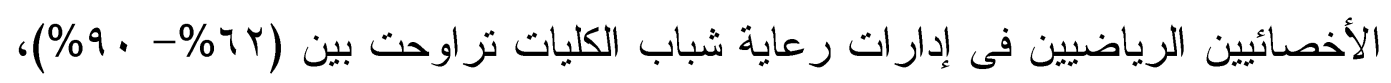

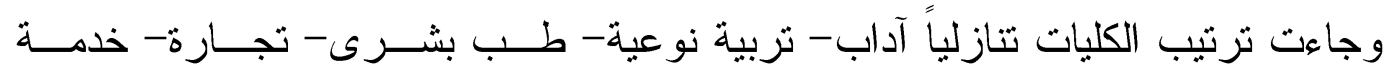




\section{\& 4}

اجتماعية- علوم وتربية رياضية- طب بيطرى- تمريض - نربية- حاسبات ومعلومات-

$$
\text { هندسة وزر اعة- صيدلة- وحقوق. }
$$

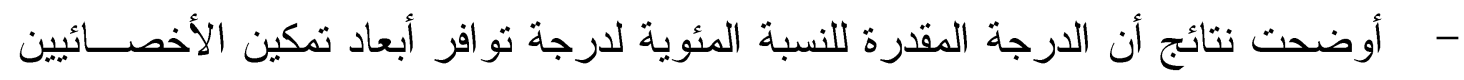
الرياضيين في إدارات رعاية شباب كلبات جامعة أسيوط كانت كالتالي:

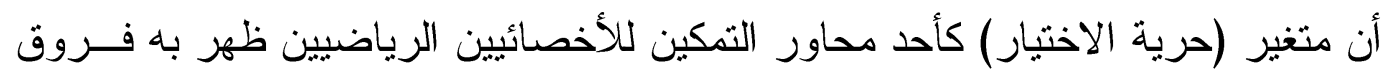

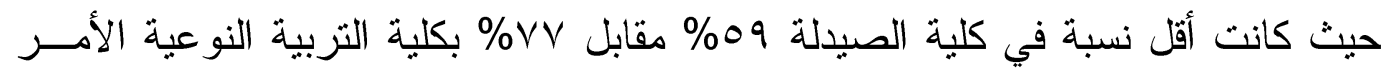

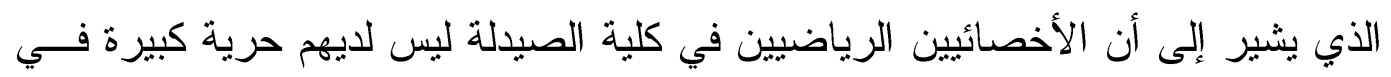
اختيار مهام عملهم بدرجة كبيزة.

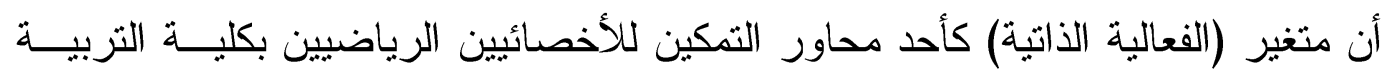

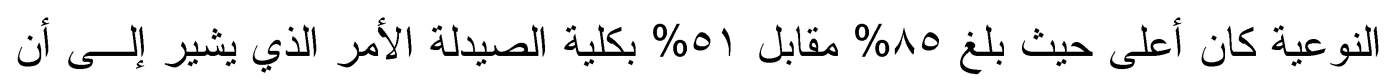

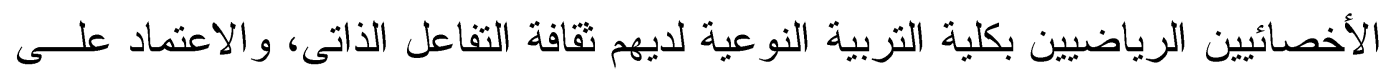

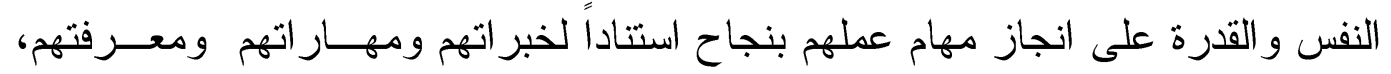

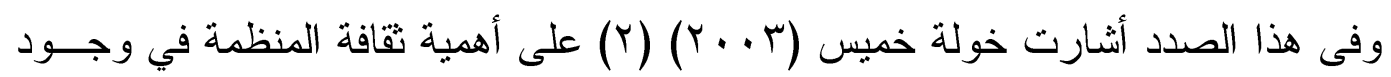

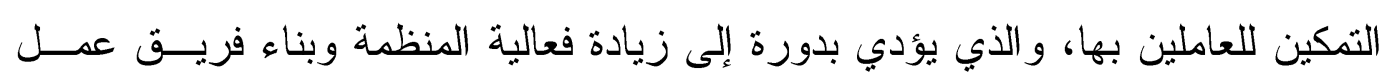
فعال.

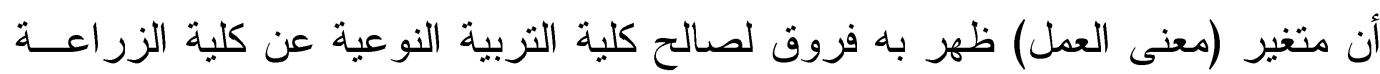

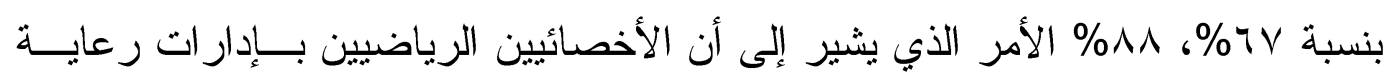

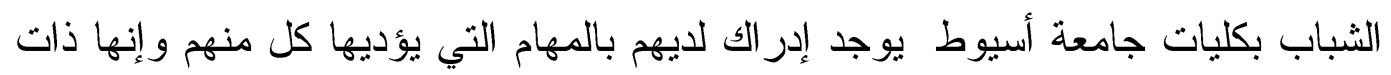

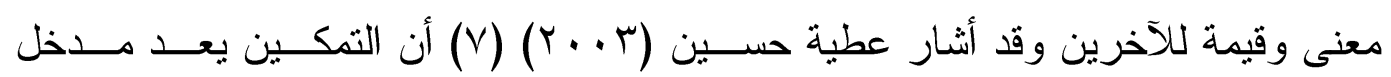

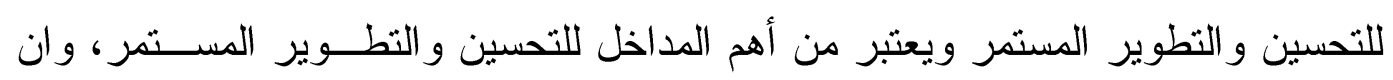

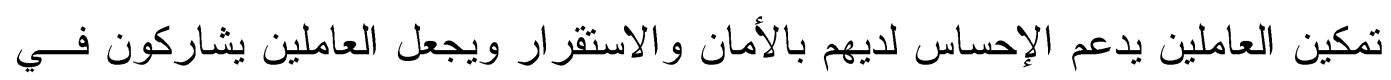
رؤية الإدارة العليا بشكل أفضل.

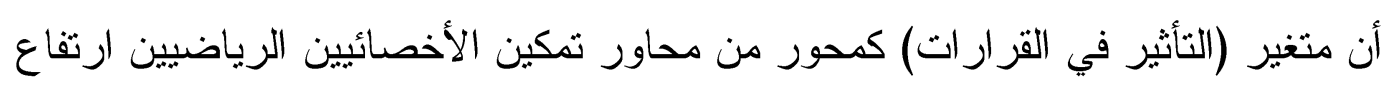

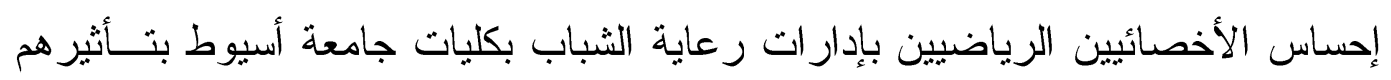

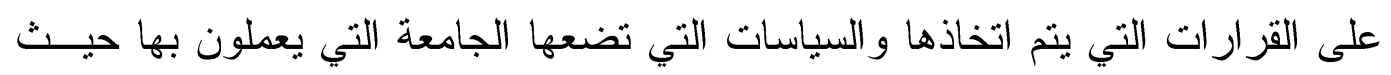

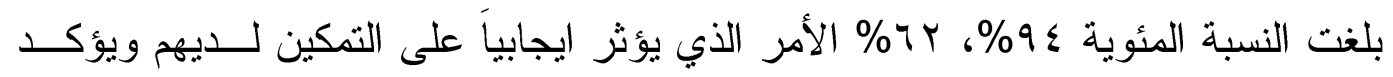

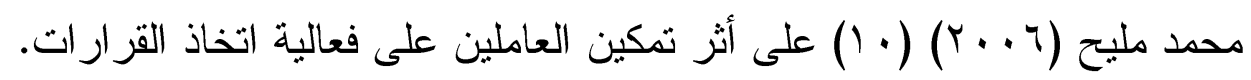




\section{$\varepsilon r v$}

- و أن مشاركة الأخصائيين الرياضيين في اتخاذ القرار ات و الإدارة الذاتبــة وســيادة روح

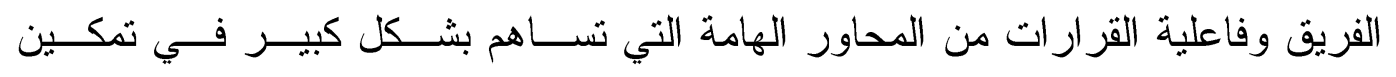

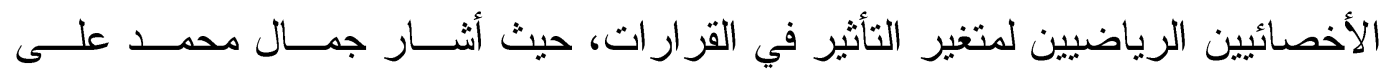

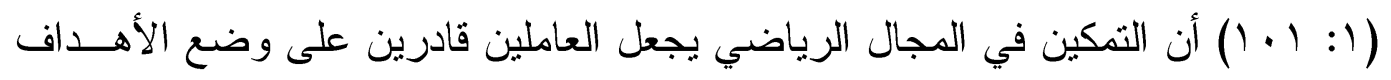
الخاصة بعملهم، و القدرة على اتخاذ القرار ومعرفة الطرق العلمية لحل المشكلات وذلك كله يتم في نطاق سلطاتهم ومسؤولياتهم. - - ومن خلال النتائج السابقة تكون الباحثة قد أجابت على التساؤل الأول للبحث ما درجـــة تو افر أبعاد تمكين الأخصائيين الرياضيين بإدارات رعاية شباب كليات جامعة أسيوط؟

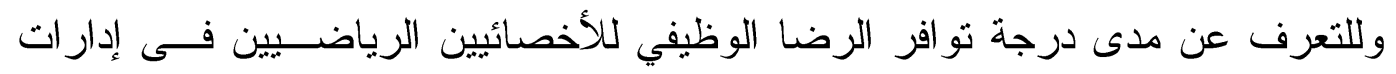

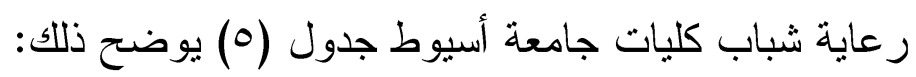
جدول (0)

النسبة المئوية للارجة المقدرة لمحاور الرضا الوظيفي لإدارات رعاية شباب كليات جامعة أسيوط

\begin{tabular}{|c|c|c|c|c|c|c|c|}
\hline 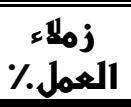 & $\begin{array}{c}11 \\
\end{array}$ & 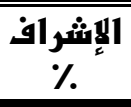 & 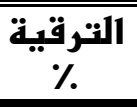 & 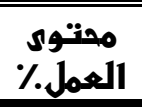 & الوظبهنة & الكابات المهاور الفر عبنة & م \\
\hline 9. & 77 & $7 \mathrm{~V}$ & $\Delta \mu$ & $\overline{V r}$ & $7 r$ & علوم (ن= 9) & 1 \\
\hline$\Lambda$. & 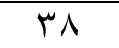 & $V$. & Ar & $V$. & VT & هندسة (ن= & $r$ \\
\hline $9 \mu$ & 01 & $\Lambda$. & 9. & VI & 19 & طب بشرى (ن =9) & $r$ \\
\hline$\Lambda V$ & rV & $O V$ & $\mathrm{Vq}$ & $7 r$ & $V \mu$ & طب بيطرى (ن= 1 () & $\varepsilon$ \\
\hline $7 V$ & rr & س & $V \varepsilon$ & 71 & $0 \leqslant$ & صبدلة (ن= V & 0 \\
\hline 7. & $\varepsilon V$ & $\varepsilon$ & 19 & 7. & 70 & تربية (ن=1 ا ) & 7 \\
\hline 77 & $\varepsilon$ & $\varepsilon \varepsilon$ & VY & 79 & $\mathrm{VI}$ & تجارة (ن= • 1) & V \\
\hline OV & $\varepsilon 1$ & $\varepsilon V$ & Vo & 09 & 00 & حقوق (ن= \& 1 ( ) & $\Lambda$ \\
\hline$\Lambda r$ & $0 \wedge$ & Vo & Ar & 19 & or & تربية رياضية (ن= Y I) & 9 \\
\hline 77 & 0. & $7 V$ & $\Lambda \varepsilon$ & VY & $7 \varepsilon$ & خدمة اجتماعية (ن=) & 1. \\
\hline$\wedge 7$ & $\leqslant 0$ & or & $\Lambda$. & r & 77 & آداب (ن= II & 11 \\
\hline VY & ry & $\leqslant 9$ & VY & 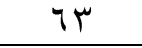 & 71 & زر اعة (ن=ي & $1 Y$ \\
\hline Vo & rV & $\mathrm{V} \cdot$ & $\Lambda \varepsilon$ & OV & 71 & تمريض (ن=1/) & 11 \\
\hline$\wedge 7$ & or & $V \cdot$ & 10 & $\Lambda$. & 19 & تربية نوعية (ن=يم) & $1 \leq$ \\
\hline$\Lambda$. & ro & $\varepsilon r$ & $\wedge 1$ & 07 & r & حاسبات و معلو مات (ن =9) & 10 \\
\hline
\end{tabular}

$$
\text { يتضح من جدول (Y) ما يلى: }
$$

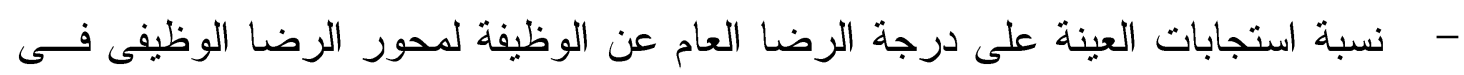

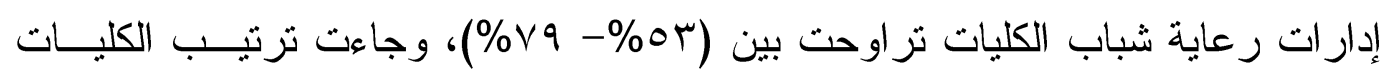
تنازلياً طب بشرى وتربية نوعية- هندسة وطب بيطرى- تجارة- آداب- تربية- خدمة

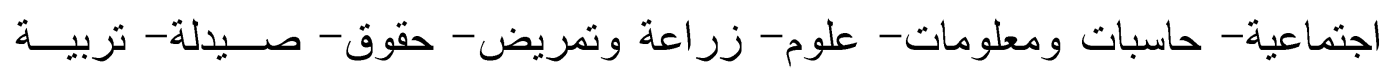
رياضبة. 


\section{$\varepsilon \mu \wedge$}

- - نسبة استجابات العينة على درجة الرضا العام عن محتوى العمل لمحور الرضا الوظيفى

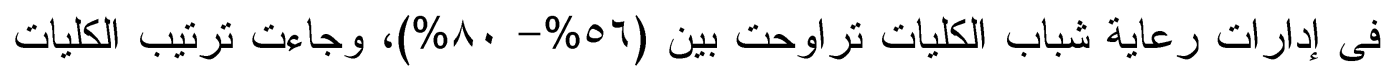
تنازلباً تربية نوعية- تربية رياضية- علوم- خدمة اجتماعية- طب بشرى- هندســة تجارة- آداب وزر اعة- طب بيطرى- صيدلة- تربية- حقوق - تمــريض- - حاسـبات و معلومات.

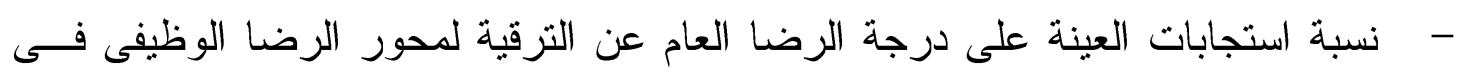

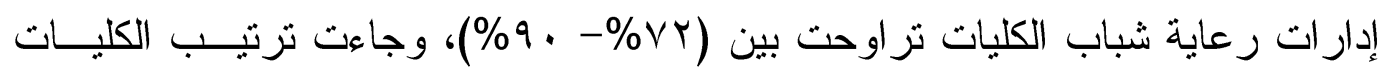

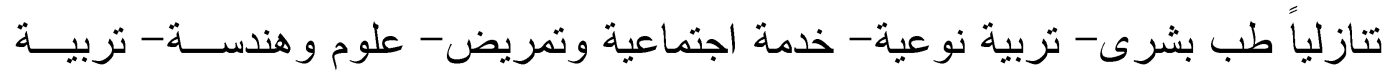
رياضية- حاسبات ومعلومات- آداب- طب بيطرى وتربية- حقوق - صيدلة- تجــارة وزر اعة.

- نسبة استجابات العينة على درجة الرضا العام عن نمط الإشر اف لمحور الرضا الوظيفى

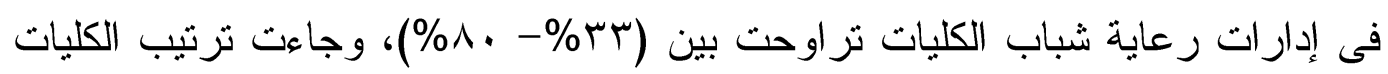
تنازلياً طب بشرى- تربية رياضية- هندسة وتمريض وتربية نوعية- علــوم وخدمــة

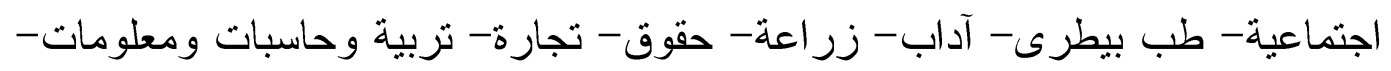

صيدلة.

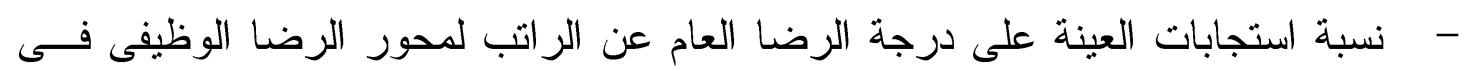

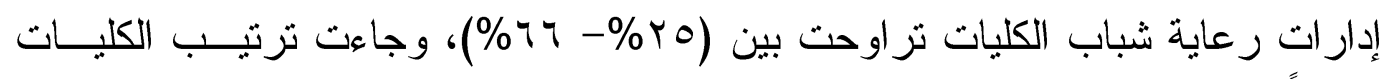

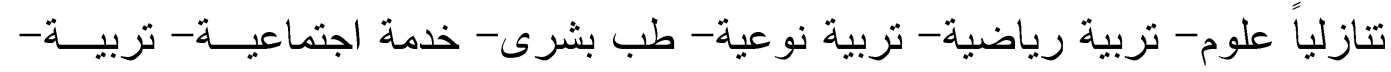

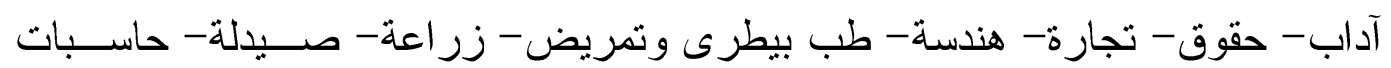

و معلومات.

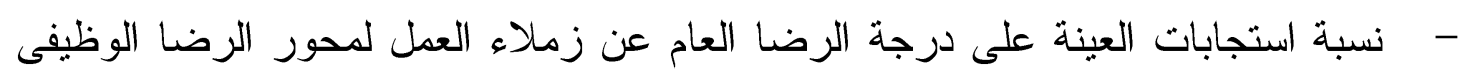

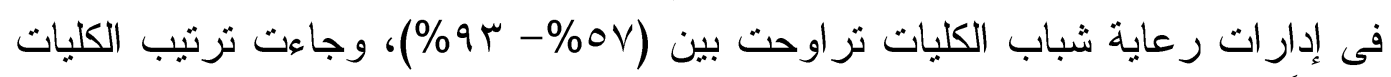
تنازلياً طب بشرى- علوم- طب بيطرى- آداب وتربية نوعية- تربية رياضية- هندسة

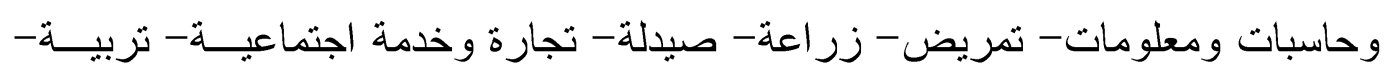
حقوق.

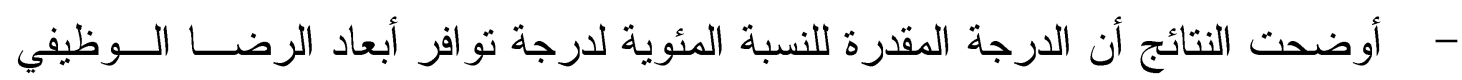
لاى الأخصائين الرياضيين بإدار ات رعاية الثباب بكليات جامعة أسيوط جاءت بياناتها كالتالي: - ارتفاع متغير (الرضا عن الوظيفة) كأحد محاور الرضا الوظيفي لدى العاملين بــإدارات

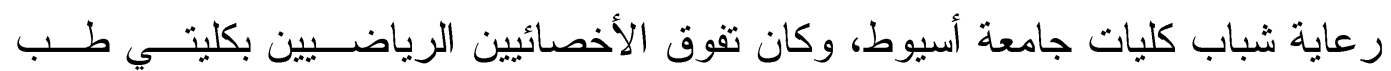




\section{$\varepsilon r q$}

بشري وكلية التربية النوعية أعلى حيث بلغ و٪\% مقابل كلية الصبدلة ro\% الأمر الذي يشير إلى أن هناك رضا تام للأخصائيين الرياضينين. - وشعور هم بالرضا والارتياح في العمل وعن المناخ والجو الذي يعمل به الفرد، وجــاء الأخصائيين الرياضيين بكلية الطب البشرى وكلية التربية النوعية أفضل من الأخصائين الرياضبين بكلية الصيدلة.

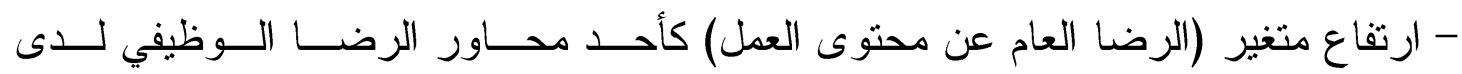

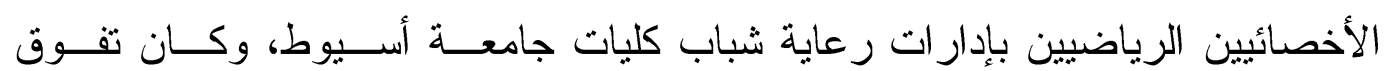
الأخصائيين الرياضيين بكلية التربية النوعية أعلى حيث بلغ ، ر\% مقابل كلية الحاسبات

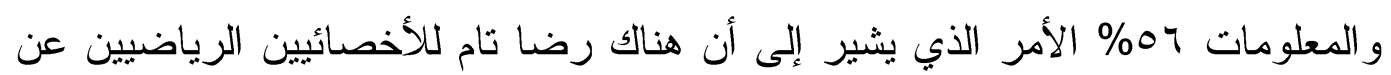
محتوى العمل الذي يقومو ا به و إتاحة الفرصة للإبداع و الابتكار في العمل و التجديد و البعد

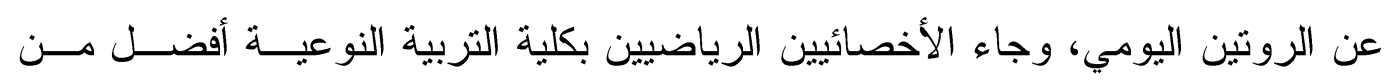
العاملين بكلية الحاسبات و المعلومات. - ارتفاع متغير (الرضا العام عن الترقية) كأحد محاور الرضـا الوظيفي لــدى الأخصـــائين

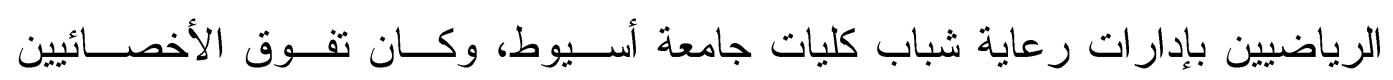
الرياضبين بكلية الطب البشرى أعلى حيث بلغ ، 9\% مقابل كليتى التجـــارة و الزر اعـــة \% الأمر الذي يشير إلى أن هناك رضا للأخصائين الرياضيين عن الأسلوب المتبع للترقبة.

- حصلت كليات طب بشرى، تربية رياضية، هندسة، تمريض، ثربية نوعية، علوم، خدمــة

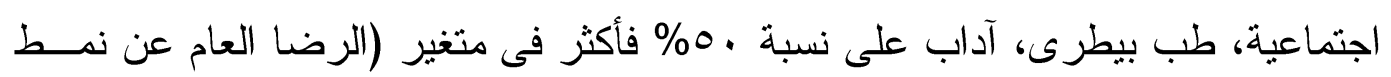
الإشر اف) مما يدل على قناعة الأخصائيين الرياضيين بإدارات رعاية شباب هذه الكليات

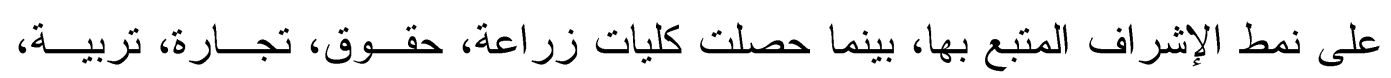

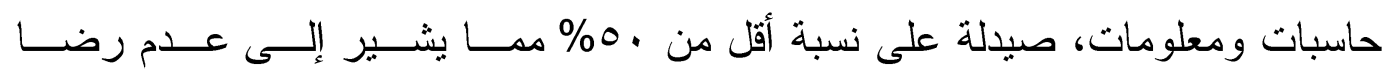
الأخصائين الرياضيين على نمط الإشر اف المتبع فى إدارات تلك الكليات.

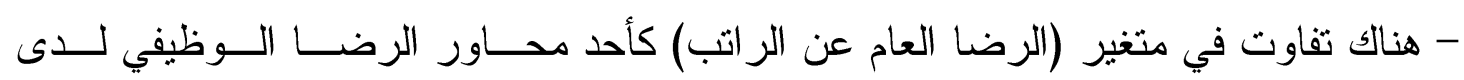

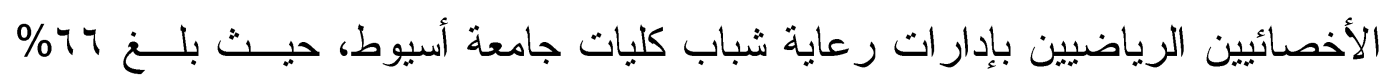

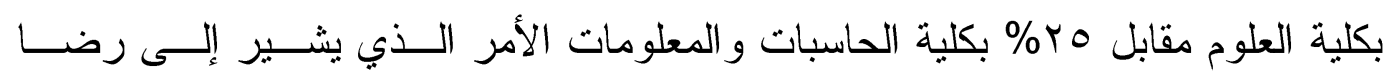
الأخصائيين الرياضيين بكليات علوم، نربية رياضية، تربية نوعية، طب بشرى، خدمــة اجتماعية عن قيمة الر اتب الذي يتقاضاه الفرد بينما جاءت نتائج الأخصائين الرياضبين 


\section{$\varepsilon \varepsilon$.}

بكليات تربية، آداب، حقوق، تجارة، هندسة، طب بيطرى، تمريض، زر اعة، صــبدلة،

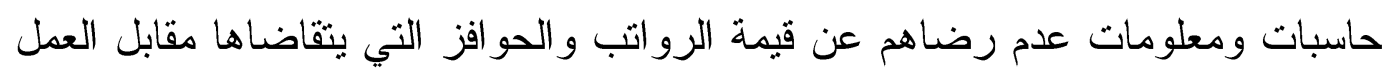
الذين يقوموا به، و عدم مناسبتها مع تكاليف المعيشة. - ارتفاع متغير (الرضا العام عن الزملاء) كأحد محاور الرضا الوظيفي لــدى الأخصـــائيين الرياضيين بإدار ات رعاية شباب كليات جامعة أســيوط، وكــان تفــوق الأخصــائين الرياضيين بكلية الطب البشرى أعلى حيث بلغ سو\% مقابل كلية الحقوق Vov\% الأمسـر الذي يشير إلى أن هنالك رضا بين الأخصائيين الرياضيين ومــدى تعــاونهم و المحبــة و التفاهم بينهم وجاءت كلية الطب البشرى في المرتبة الأولى.

- و تتفق نتائج هذه الدر اسة مع در اسة Smucker \& Pedersen (Y... (Y) (Y) فى رضا العاملين عن وظائفهم وزملاء العمل بينما اختلفت هذه الدراسة فى الرضـا عــن الترقيـة و عدم الرضا عن نمط الإشر اف وتزى الباحثة أن الاختلاف يرجع إلى اختلاف طبيعــة العمل داخل كل منظمة وطبيعة المهام و الإعمال التى يؤديها كل فرد فى المنظمة. ومن خلال النتائج السابقة تكون الباحثة قد أجابت على التساؤل الثاني للبحث ما مدى درجة تو افر أبعاد الرضا الوظيفي لدى الأخصائيين الرياضيين بإدار ات رعاية شباب كليــات جامعة أسيوط؟

قامت الباحثة بدر اسة العلاقة بين أبعاد تمكين الأخصائين الرياضبين و الرضا الوظيفى بإدار ات رعاية شباب كليات جامعة أسيوط كما هو موضح بجدول (T) على النحو التالى:

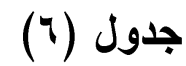

العلاقة بين أبعاد تمكين الأخصائيين الرياضيين والرضا الوظيفى بإدارات رعاية شباب كليات جامعة أسيوط

\begin{tabular}{|c|c|c|c|c|c|c|c|c|c|c|c|c|c|c|c|}
\hline هاسبات & نوعية & تمريض & زراعة & آداب & خدمة & رياضية & هقور & تجارة & تربية & صيدلة & بيطري & بشري & هندسة & علوم & 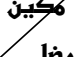 \\
\hline & & & & & & & & & & & & & & $*_{,}, V_{1}$ & علوم \\
\hline & & & & & & & & & & & & & . & & هندسة \\
\hline & & & & & & & & & & & & $*, 9 \lambda$ & & & بشري \\
\hline & & & & & & & & & & & $*, 9 \vee$ & & & & بيطر بي \\
\hline & & & & & & & & & & 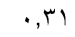 & & & & & صيدلة \\
\hline & & & & & & & & & $*, V \vee$ & & & & & & نربية \\
\hline & & & & & & & & $\cdot, \leqslant 7$ & & & & & & & تجارة \\
\hline & & & & & & & $*, \mathrm{~V} r$ & & & & & & & & حقوق \\
\hline & & & & & & $*, \lambda)$ & & & & & & & & & رياضية \\
\hline
\end{tabular}


تابع جدول (7)

العلاقة بين أبعاد تمكين الأخصائيين الرياضيين والرضا الوظيفى بإدارات رعاية شباب كليات جامعة أسيوط

\begin{tabular}{|c|c|c|c|c|c|c|c|c|c|c|c|c|c|c|c|}
\hline هاسبات & نوعية & تمريضر & زراعة & آداب & خدمة & رياضية & هقوة & تجارة & تربية & صيدلة & بيطري & بشري & هندسة & علوم & ضl \\
\hline & & & & & $*_{\cdot, \text {, }}$ & & & & & & & & & & خذمة \\
\hline & & & & $*_{*}, \mathrm{\vee} \lambda$ & & & & & & & & & & & آداب \\
\hline & & & $-\cdot, \cdot \lambda$ & & & & & & & & & & & & زر اعة \\
\hline & & .7. & & & & & & & & & & & & & تمريض \\
\hline & $*, \lambda 4$ & & & & & & & & & & & & & & نوعية \\
\hline$*_{\bullet, V}, \mathrm{r}$ & & & & & & & & & & & & & & & حانسبات \\
\hline
\end{tabular}

يتضح من جدول (ץ) ما يلي: وجود علاقة ذات دالة إحصائية عند مســتوى (0. . . )

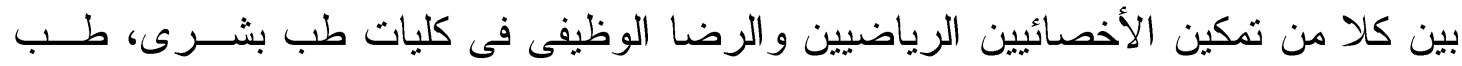

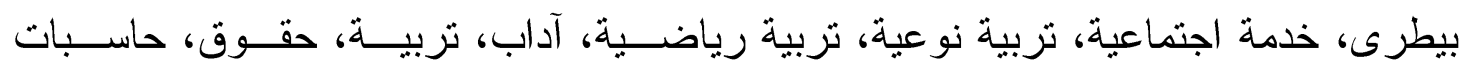

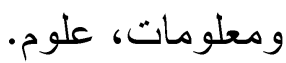
وتعزى الباحثة بوجود علاقة ذات دالة إحصائية بين كلا مــن تمكـين الأخصــائيين

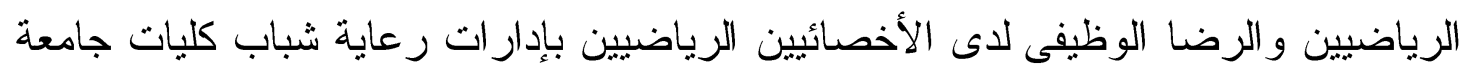

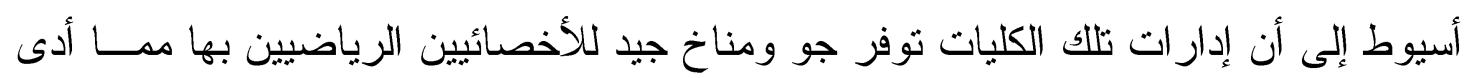

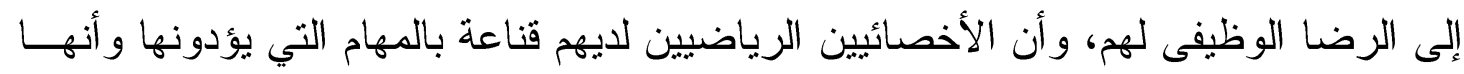

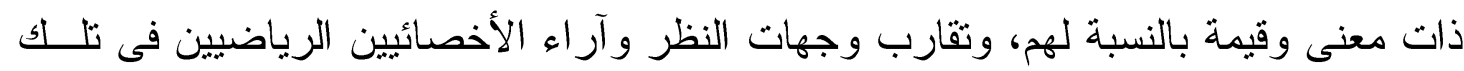

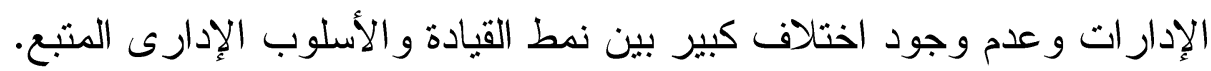

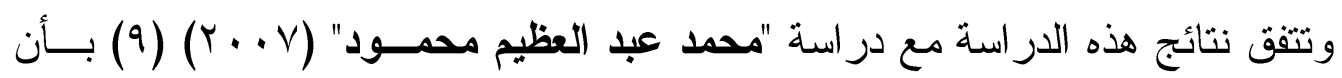

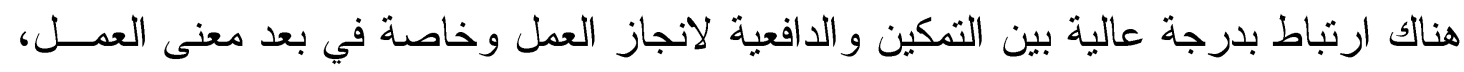

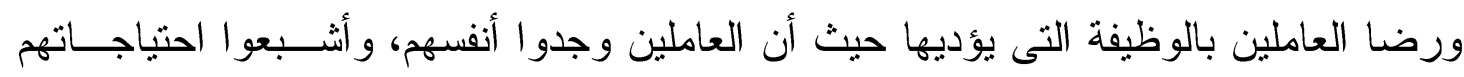
ومقتتعين بالأعمال التى يقومو ا بها.

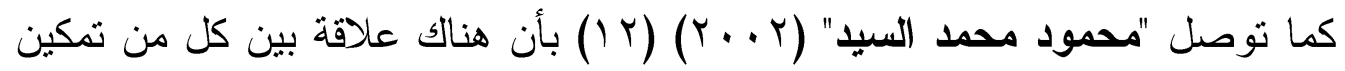

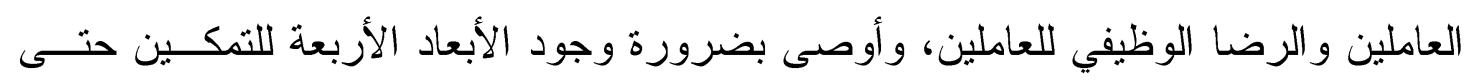
تتحقق المخرجات المطلوبة من عملية التمكين مثل الرضا الرضا الوظيفي.

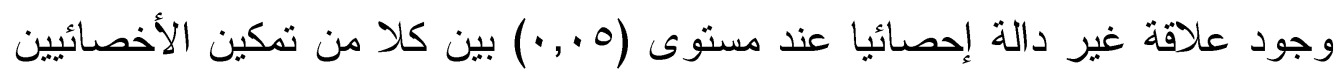

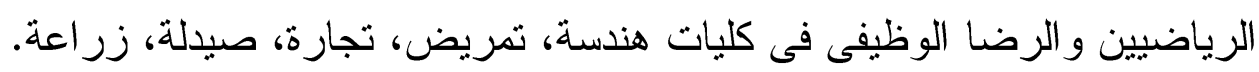

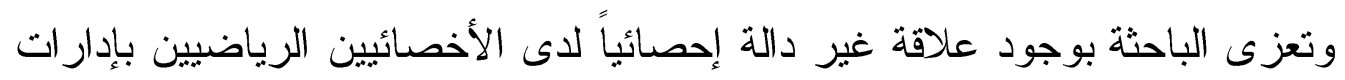

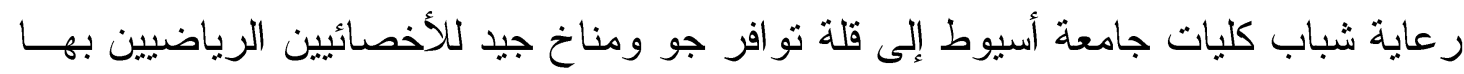
مجالة أسيوط لعلوم وفنون التربية الرياضية 


\section{$\varepsilon \leqslant r$}

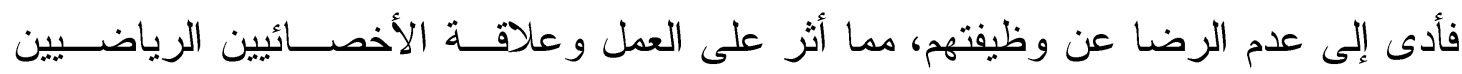
بعضهم مع بعض سو اء على مستوى الأفقى أو الر أسى. الاستخلاصات:

\section{في ضوء مناقشة وتفسير نتائج البحث استخلصت الباحثة ما يلي :}

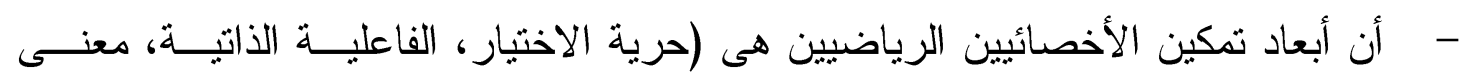

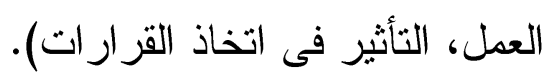
- - أن الرضا الوظيفى للأخصائيين الرياضيين منمثلة فى الاتى (الرضـا العام عن الوظيفــة،

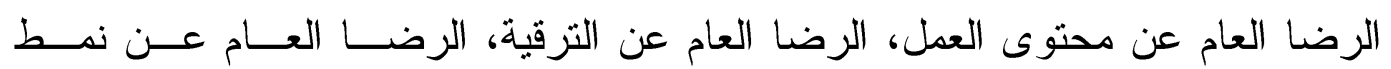
الاشر اف، الرضا العام عن الراتب، الرضا العام عن الزماءع).

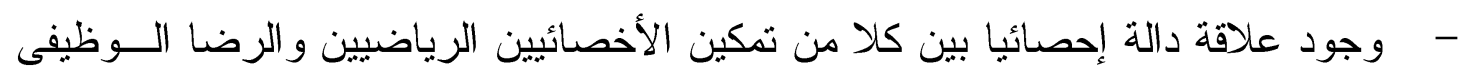
فى كليات طب بشرى، طب بيطرى، خدمة اجتماعية، تربية نوعية، تربيــة رياضــية، آداب، تربية، حقوق، حاسبات ومعلومات، علوم.

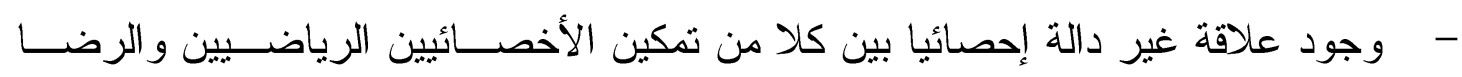
الوظيفى فى كليات هندسة، تمريض، تجارة، صيدلة، زر اعة. التوصيات:

في ضوء هدف البحث وفي حدود مجتمع البحث والعينة المختارة وفي ضــوء مــا توصل إليه من نتائج توصي الباحثة بما يلي:

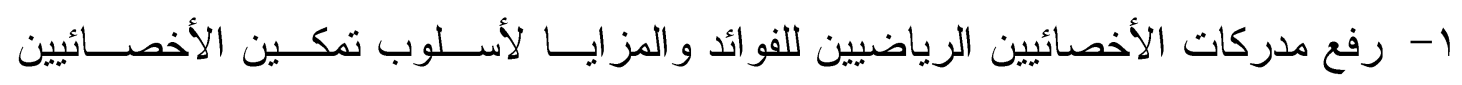
الرياضيين و أهميته لتحقيق الرضا الوظيفي للأخصائين الرياضينين.

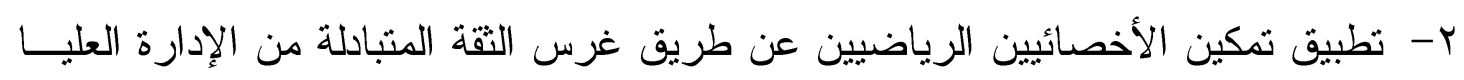

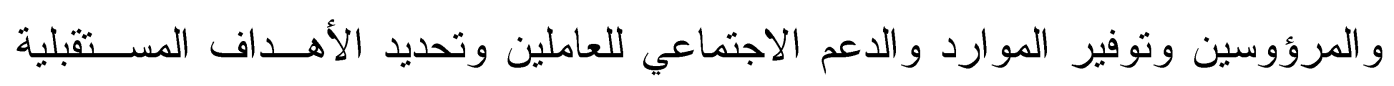
وتكوين فرق العمل و الاتصال الفعال و التدريب المستمر للأخصائيين الرياضيين. ب- زيادة مكافآت وحو افز الأخصائيين الرياضيين بإدار ات رعاية الثباب بكليــات الجامعــة

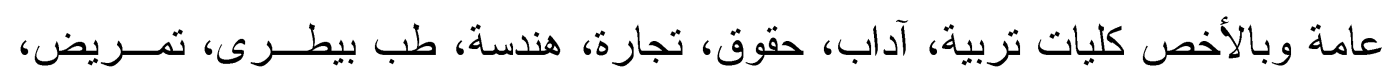

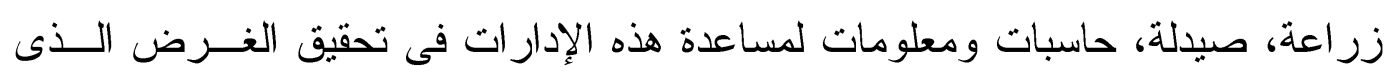
أنشئ من أجله وهو تحقيق النمو الثامل و المتزن للفرد من خلال الخدمات الرياضية. 


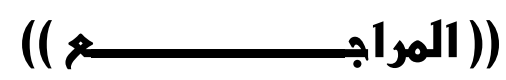

أولا: المراجم العربية:

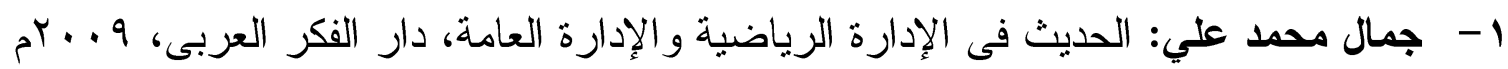

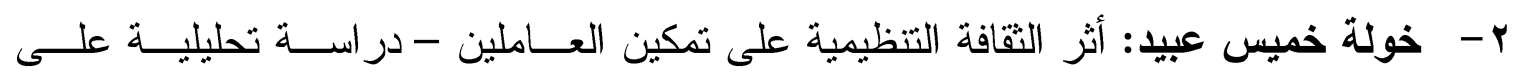

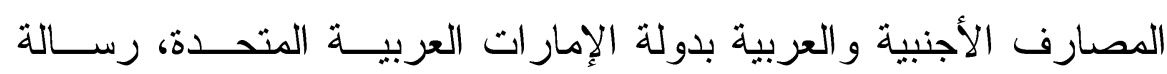

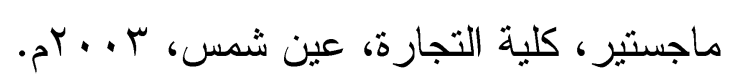

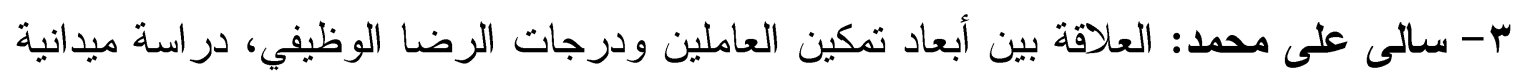

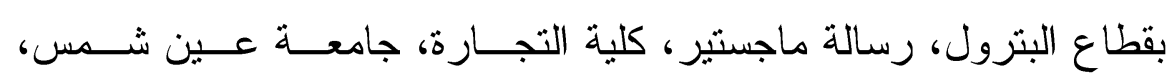

$$
\text { مrer }
$$

ع - سامية فريد محمد: العلاقة بين الثقافة التتظيمية وتمكين العاملين بالاتحاد المصري للكــرة

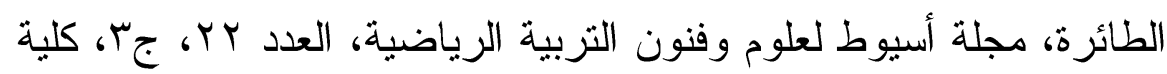

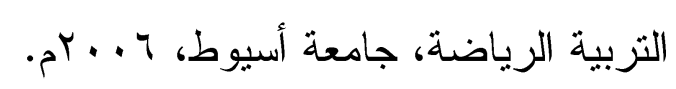

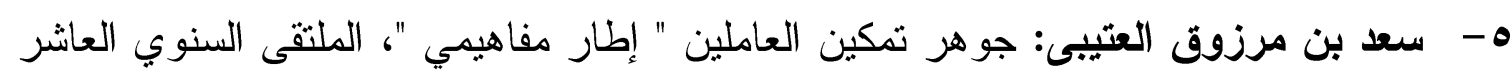

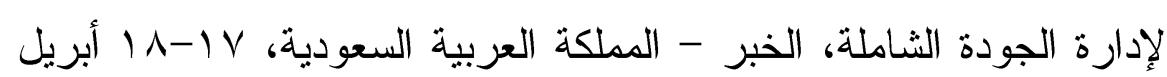

$$
\text { 5r... }
$$

צ- شرين فتحي الفقي: أثز العوامل التنظيمية على تمكين العاملين فى المنظهــات الخدميــة،

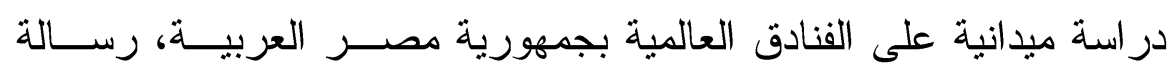

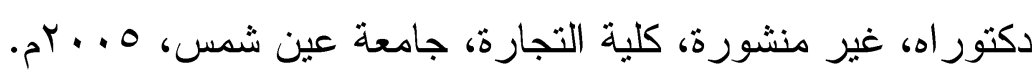

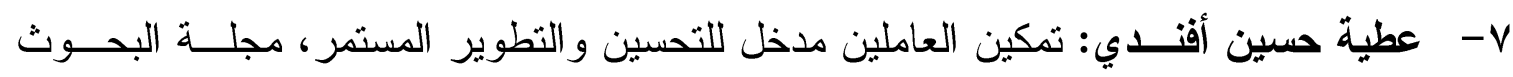

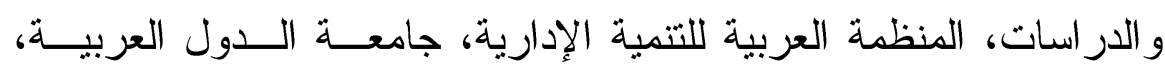

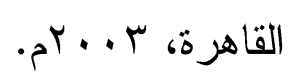

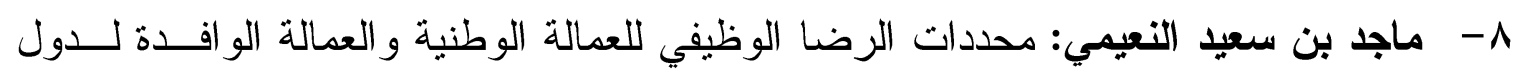

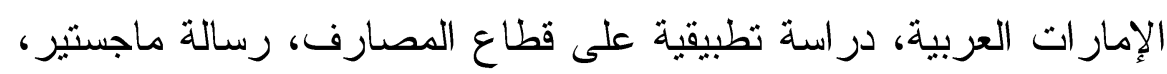

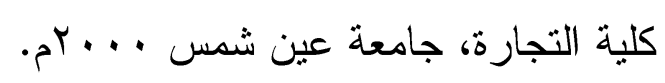

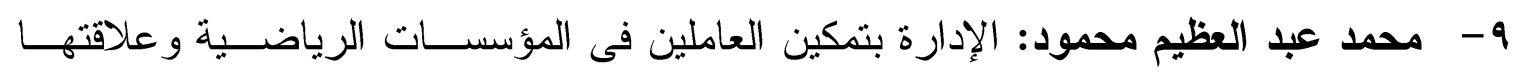

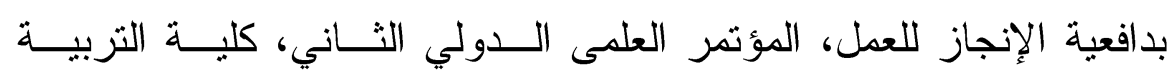

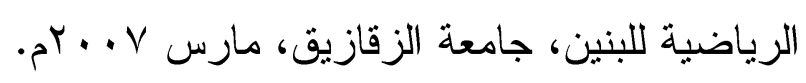




\section{$\varepsilon \varepsilon \varepsilon$}

• 1- محم فليح سـليمان: أثر تمكين العاملين على فاعلية اتخاذ القرارات، بالتطبيق على شركة

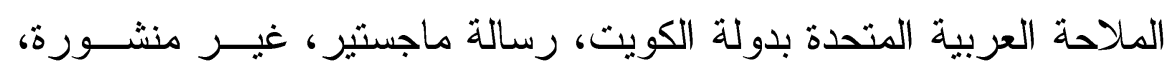

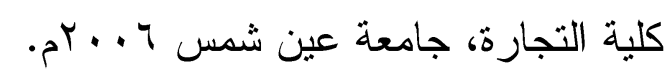

11 - محمود أحمد الخطيب: إمكانيات تمكين العاملين فى الشركات الصناعية، المؤتمر العلمـي

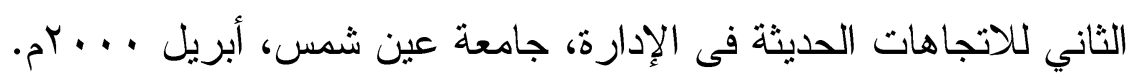

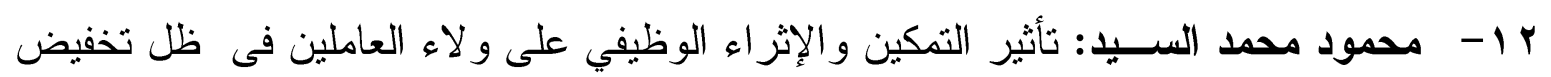

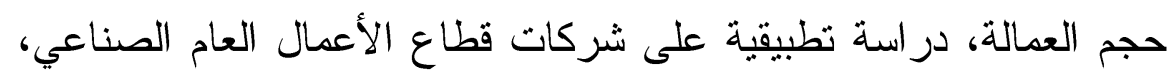
المجلة العلمية للاقتصاد و التجارة، كلية التجارة، جامعة عين شمس، العدد

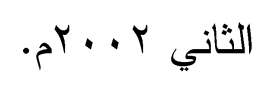

ب ا - ناصر محمد العديلي: السلوك الإنساني و التنظيمي، الرياض، معهد الإدارة العامة، 990 (م.

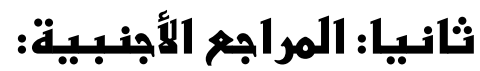

14- Bennis, W. \& Townsend, R: Reinventing leadership: Strategies to Empower the Organization. New York: William Morrow \& Company, Inc., 1995.

15- Chad - Rubel: Empower your employees so you can satisfy customers" marketing news, vol. 22, no, 6, march 1995

16- Ellinger, A., D., S: Supervisory coaching behavior, employee satisfaction, and warehouse employee performance: A dyadic perspective in distribution industry. Human resource development quarterly, 14, Issue 4, 435-458, 2003.

17- Furnham, A., Petrides, K., Jackson, C. \& Cotter, T: Do personality factors predict job satisfaction. Personality and individual Differences, V.33. Issue 8, 1325-1342. 2002.

18- Gritchen M. Spreitzer. et al: Dimensional Analysis of the relationship between psychological. Empowerment and effectiveness satisfaction and stain strain journal of management, vol. 23, no, 5, 1997. 
19- Micheal Hartline and O. C. Ferrel: the management of customer contact service employees: An empirical investigation, journal of Marketing, Vol. 60, no. 40, Oct. 1996.

20- R. E. Quinn, \& G. M. Spritizer: "the Road to empowerment seven Questions every leader should consider," Organizational dynamics, Vol. 26, No. 2, 1997.

21- Smucker, M., Whisenant, W., \& Pedersen: An investigation of job satisfaction and female sports journalist. Sex Roles, V.49, 401-407(7) P, 2003.

نالناً: شبكة المعلومات (1الإنتنرنتـ)

22- httpen Duval-\%E2\%80\%93chery\&a=Phptitle orgwinvdex. Ipedia, wikipedia. orgwindex. 